\title{
Transatlantic Trade and Investment Partnership, and Environmental Consequences
}

\author{
Dhimitri Qirjo ${ }^{1+}$, Razvan Pascalau ${ }^{1}$, and Robert Christopherson ${ }^{1}$ \\ ${ }^{1}$ SUNY Plattsburgh, USA
}

\begin{abstract}
We empirically investigate the effect of the Transatlantic Trade and Investment Partnership on the per capita emissions of eight air pollutants and municipal waste. By introducing the same explanatory variables and applying the same empirical strategy and methodologies as in Qirjo and Pascalau (2019), we provide robust evidence suggesting that the implementation of the partnership could be beneficial to the environment because it may reduce per capita emissions of $\mathrm{CH}_{4}$, hydrofluorocarbons/ perfluorinated chemicals/ $\mathrm{SF}_{6}, \mathrm{~N}_{2} \mathrm{O}, \mathrm{NH}_{3}$, and $\mathrm{SF}_{6}$ for a typical partnership member. This result is based on statistically significant evidence showing that, on average, the pollution haven motive based on national per capita income variations is dominated by the factor endowment argument based on the Heckscher-Ohlin trade theory and the pollution haven motive originating from an inverse measurement of national population density differences. However, we also report statistically significant evidence that the implementation of the partnership could denigrate the environment by increasing per capita emissions of $\mathrm{SO}_{2}$ and municipal waste.
\end{abstract}

Keywords: Free Trade, Environmental Economics, TTIP, Transatlantic Trade and Investment Partnership

JEL Classifications: F18, F53, F64

Received 18 June 2020, Revised 1 September 2021, Accepted 23 September 2021

\section{Introduction}

The Transatlantic Trade and Investment Partnership (TTIP) is a potential free trade agreement on goods and services between the U.S. and the EU. TTIP has the potential to be the largest free trade area in the world, serving about 800 million people on both sides of the Atlantic. Note that a year before the 2019 novel coronavirus disease pandemic, the trade volume between the US and the EU was US\$1 trillion. Various economic projections estimate that the creation of a free trade area between the U.S. and the EU may increase their gross domestic products (GDP) by about $0.5 \%$ and $0.4 \%$, respectively.

Negotiations over TTIP were launched in 2013 during the Obama administration and were

+Corresponding Author: Dhimitri Qirjo

Associate Professor, Department of Economics \& Finance, SUNY Plattsburgh, 329 Au Sable Hall, 101

Broad St., Plattsburgh, NY, 12901, USA. Email: dqirj001@fiu.edu

Co-Author: Razvan Pascalau

Associate Professor, Department of Economics \& Finance, SUNY Plattsburgh, 325 Au Sable Hall, 101

Broad St., Plattsburgh, NY, 12901, USA. Email: rpasc001@plattsburgh.edu

Co-Author: Robert Christopherson

Professor and Chair of the Department of Economics \& Finance, SUNY Plattsburgh, 203 Au Sable Hall,

101 Broad St., Plattsburgh, NY, 12901, USA. Email: christrl@plattsburgh.edu 
very close to reaching the final agreement a year later. These negotiations continued on very optimistic terms until May 2016, when a leak from Greenpeace Netherlands revealed Thirteen Chapters of the Agreement (including a chapter associated with the potential environmental effects of TTIP entitled "Raw Materials and Energy"1) that discusses the environmental issues and goals associated with the implementation of TTIP). Moreover, Great Britain voted to leave the EU in June 2016 (known as the "Brexit"). These two events postponed the plan to put the TTIP agreement in 2016.

In 2017, the Trump administration halted TTIP negotiations, and a year later, escalated a trade war between the US and the EU. On the other side of the Atlantic, after observing the populist approach of the Trump administration toward trade with the EU, the European Commission also concluded that TTIP negotiations were no longer relevant. However, it appears that the newly elected Biden administration has raised the hope of a potential trade agreement between the US and the EU. President Biden's attitude is far more open toward global free trade in general, and several political and economic policy experts expect negotiations over TTIP to resume and gain momentum during his presidency.2)

It is important not only for academic purposes, but also for policy implications, to examine the possible effects that such a large trade deal could have on air pollution and municipal waste on both sides of the Atlantic. In their study, Qirjo and Pascalau (2019b) were the first to analyze the possible effect of TTIP on greenhouse gases (GHGs) and carbon dioxide $\left(\mathrm{CO}_{2}\right)$. They show that the implementation of TTIP could help reduce the per capita emissions of these air pollutants for a typical TTIP member. However, there are other air pollutants that could be affected by this trade deal, which were absent in the analysis of Qirjo and Pascalau (2019b).3) For example, although they find a reduction in GHGs and $\mathrm{CO}_{2}$ from the implementation of TTIP, other air pollutants that are part of GHGs might not follow the same relationship. This could be because $\mathrm{CO}_{2}$ accounts for approximately $75 \%$ of all GHGs, and the former pollutant may drive the result of the latter. Other empirical studies have shown this to be the case: for example, Qirjo, Pascalau, and Krichevskiy (2019), Qirjo, Pascalau, and Krichevskiy (2020) and Qirjo, Pascalau, and Krichevskiy (2021) have shown that the implementation of the Comprehensive Economic and Trade Agreement (a free trade agreement between Canada and the EU) could help decrease per capita emissions of GHGs and $\mathrm{CO}_{2}$, respectively, but increase per capita emissions of fluorinated gases (F-gases).

One of the important objectives of this paper is to analyze the effect of TTIP on other than $\mathrm{CO}_{2}$ air pollutants that are part of GHGs, such as $\mathrm{CH}_{4}$ (methane), $\mathrm{N}_{2} \mathrm{O}$ (nitrous oxide), and hydrofluorocarbons

1) For more details, see the technical report available online: http://rade.ec.europa.eu/doclib/docs/2016/august/tradoc_154837.pdf

2) See, for example, https://ec.europa.eu/commission/presscorner/detail/en/ip_20_2279, https://www.atlanticcouncil.org/wpcontent/uploads/2021/01/Relaunching-the-Transatlantic-Trade-Agenda.pdf, and https://www.wilsoncenter.org/article/e nhancing-transatlantic-trade-and-investmentrelationship, inter alia, for recent opinions from political and economic policy experts on the future of TTIP.

3) It could be important to note here that we use a more recent time period (1990-2018) and exclude the UK (as it is not officially part of the EU) from our dataset, while Qirjo and Pascalau (2019b) use the time period 1989-2013 and include the UK in the dataset. Two earlier working paper versions of the current study [for more details, see Qirjo and Pascalau (2019a) (Qirjo, et al. (2020)] use the exact same dataset in terms of time period and the list of TTIP members (1989-2013 with the UK included in the list of the EU members) compared with the one used in Qirjo and Pascalau (2019b). 
(HFCs) / perfluorinated chemicals (PFCs)/ $\mathrm{SF}_{6}$ (F-gases). The results of the current study show that per capita emissions of each group of GHGs other than $\mathrm{CO}_{2}\left(\mathrm{CH}_{4}, \mathrm{HFCs} / \mathrm{PFCs} / \mathrm{SF}_{6}\right.$, and $\left.\mathrm{N}_{2} \mathrm{O}\right)$ could be decreased by the implementation of TTIP.

The second important objective is to examine the possible implementation of TTIP on air pollutants other than GHGs because they are also affected by this large trade deal. There is a large corpus of theoretical and empirical literature that analyzes air pollutants that are affected by free trade agreements. In addition to the GHGs mentioned above, other important air pollutants that are affected by trade agreements are $\mathrm{SO}_{2}$ (sulfur dioxide), sulfur oxides ( $\mathrm{SO}_{\mathrm{x}}$ ), nitrogen oxides $\left(\mathrm{NO}_{\mathrm{x}}\right), \mathrm{SF}_{6}$ (sulfur hexafluoride), and $\mathrm{NH}_{3}$ (ammonia). For instance, Antweiler et al. (2001) focused on the role of freer trade in $\mathrm{SO}_{2}$ emissions. Cole (2003), Cole and Elliott (2003), and Frankel (2009) show the importance of freer trade on per capita emissions of $\mathrm{SO}_{\mathrm{x}}, \mathrm{NO}_{\mathrm{x}}, \mathrm{SF}_{6}$, and $\mathrm{NH}_{3}$.

The results of the current study imply that the implementation of TTIP may help reduce per capita emissions of $\mathrm{NH}_{3}$ and $\mathrm{SF}_{6}$, respectively, but may increase per capita emissions of $\mathrm{SO}_{2}$ for a typical TTIP member.

A large body of literature emphasizes the role of trade openness in solid municipal waste. For more details on this literature, see Cole et al. (1997), Cole (2003), and Mazzanti and Zoboli (2009). Consequently, the third objective of this study is to analyze the possible effect of TTIP on municipal waste. Our results indicate that the per capita emissions of municipal waste could increase from the implementation of the TTIP.

In this study, we employ the same empirical methodology used in Qirjo and Pascalau (2019b), but here we focus on nine pollutants. Using data for 1990-2018 for $27 \mathrm{EU}$ members and the US, we empirically investigate the role of the implementation of the TTIP on per capita emissions of eight air pollutants: $\mathrm{SO}_{2}, \mathrm{SO}_{\mathrm{x}}, \mathrm{CH}_{4}, \mathrm{HFCs} / \mathrm{PFCs} / \mathrm{SF}_{6}, \mathrm{~N}_{2} \mathrm{O}, \mathrm{NO}_{\mathrm{x}}, \mathrm{SF}_{6}$, and $\mathrm{NH}_{3}$, and one mostly solid pollutant, municipal waste.

We find statistically significant evidence suggesting that the implementation of TTIP may reduce per capita emissions of $\mathrm{CH}_{4}, \mathrm{HFCs} / \mathrm{PFCs} / \mathrm{SF}_{6}, \mathrm{~N}_{2} \mathrm{O}, \mathrm{NH}_{3}$, and $\mathrm{SF}_{6}$. More specifically, holding all other factors constant, we show that, on average, a $1 \%$ increase in bilateral trade between the US and a typical EU member may reduce per capita emissions of $\mathrm{CH}_{4}, \mathrm{HFCs} / \mathrm{PFCs} / \mathrm{SF}_{6}, \mathrm{~N}_{2} \mathrm{O}, \mathrm{NH}_{3}$, and $\mathrm{SF}_{6}$ by about 4,5 , and $4 \mathrm{~kg}$ in $\mathrm{CO}_{2}$ in-equivalent, 26 metric tons $(\mathrm{Mt})$, and 574 tons $(\mathrm{T})$ in $\mathrm{CO}_{2}$ in-equivalent, in a year, respectively.

However, we also found potential environmental degradation from the implementation of TTIP. In particular, holding everything else constant, we report statistically significant evidence suggesting that a $1 \%$ increase in bilateral trade between the US and a typical EU member may increase yearly per capita emissions of $\mathrm{SO}_{2}$ and municipal waste by about $810 \mathrm{~g}$ and $2360 \mathrm{~kg}$, respectively. For $\mathrm{SO}_{\mathrm{x}}$ and $\mathrm{NO}_{\mathrm{x}}$, the results of the trade intensity coefficients either indicate alternate signs dependent on the empirical methodology and/ or the models used in this study, or they are not statistically significant.

On the one hand, a typical EU member has a lower per capita GDP and is more densely populated than the US; thus, a poor country may act as a pollution haven (one) because it adopts lax environmental laws 
following "Pollution Haven Hypothesis One" (which is based on national per capita income differences).

On the other hand, the US may act as a pollution haven (two) because it is sparsely populated compared with a typical TTIP member according to "Pollution Haven Hypothesis Two" (which is generated from national density of population variations). Consequently, the US may produce pollution-intensive goods at cheaper prices, and, therefore, export them to the EU [see, for example, Frankel and Rose (2005), which was the first empirical study to introduce this hypothesis) owing to the implementation of TTIP.

In the case of $\mathrm{CH}_{4}, \mathrm{HFCs} / \mathrm{PFCs} / \mathrm{SF}_{6}, \mathrm{~N}_{2} \mathrm{O}, \mathrm{NH}_{3}$, and $\mathrm{SF}_{6}$, the US may act as a pollution haven because of the implementation of TTIP if Pollution Haven Hypothesis One is dominated by Pollution Haven Hypothesis Two. If this is the case, then the factor endowment hypothesis (which claims that capitalabundant countries pollute the environment more when they trade with labor-abundant countries) may further denigrate the environment in the US, as the US is a capital-abundant country compared with an average TTIP member. Thus, the US would export capital-intensive goods (considered pollutionintensive goods) to a typical labor-abundant EU member and import labor-intensive goods (considered environmentally friendly goods) from an average EU member owing to the implementation of TTIP. Analogously, a typical TTIP member may act as a pollution haven if Pollution Haven Hypothesis One dominates Pollution Haven Hypothesis Two. However, under this scenario, the implementation of TTIP could still be beneficial to the environment for a typical TTIP member if the factor endowment hypothesis dominates Pollution Haven Hypothesis One.

Our empirical results show that the implementation of TTIP, on average, may reduce global warming because it could reduce the per capita emissions of $\mathrm{CH}_{4}, \mathrm{~N}_{2} \mathrm{O}, \mathrm{NH}_{3}$, and $\mathrm{SF}_{6}$. This is because we observed stronger factor endowment hypothesis and Pollution Haven Hypothesis Two than Pollution Haven Hypothesis One for these four air pollutants. In other words, more openness to trade between the US and the EU could reduce per capita emissions of $\mathrm{CH}_{4}, \mathrm{~N}_{2} \mathrm{O}, \mathrm{NH}_{3}$, and $\mathrm{SF}_{6}$ because they are labor-abundant and densely populated; the typical EU member appears to be more environmentally efficient despite being poorer than the US. This result is consistent with Qirjo and Pascalau's (2019b) conclusion; they use the same empirical methodology and explanatory variables as we did in the current study, and provide robust evidence suggesting that the implementation of TTIP may help reduce per capita $\mathrm{CO}_{2}$ and $\mathrm{GHG}$ emissions, respectively. This is also consistent with the conclusions of Qirjo et al. (2021), who empirically analyzed the effects of the Comprehensive Economic and Trade Agreement on four main GHGs for the 1990-2016 time period. They show that the implementation of this agreement could contribute to the fight against global warming because it may reduce per capita emissions of $\mathrm{CO}_{2}, \mathrm{CH}_{4}, \mathrm{HFCs} / \mathrm{PFCs} / \mathrm{SF}_{6}$, and $\mathrm{N}_{2} \mathrm{O}$, respectively.

Our empirical findings imply that the implementation of TTIP supports the race to the top hypothesis for $\mathrm{CH}_{4}, \mathrm{HFCs} / \mathrm{PFCs} / \mathrm{SF}_{6}, \mathrm{~N}_{2} \mathrm{O}, \mathrm{NH}_{3}$, and $\mathrm{SF}_{6}$, and is consistent with theoretical models that analyze the role of strategic trade policies on the environment. In particular, Bommer and Schulze (1999) develop a model with politically endogenous (independent from the trade regime) environmental policy and show that trade liberalization reduces pollution. Burguet and Sempere (2003) design a theoretical 
framework similar to Brander and Spencer (1985) to show how strategic trade distortions in environmental policies change in the face of trade reduction in a two-country world, where countries are symmetric. They conclude that lower trade barriers tend to reduce the incentives to increase the pollution associated with trade in both countries. Lai and Hu (2008) apply a strategic trade model to analyze trade agreements and global welfare when domestic environmental policies are not feasible. They find that tariff reductions by all trade members are beneficial to the global environment.

However, our empirical findings suggest that the implementation of TTIP could increase global warming, as it may increase the per capita emissions of $\mathrm{SO}_{2}$ and municipal waste. The empirical findings of this study imply that the implementation of TTIP will follow the race to the bottom hypothesis for $\mathrm{SO}_{2}$ and municipal waste, and will support theoretical frameworks that analyze the effect of strategic trade policies on pollution. For example, Copeland and Taylor (1995) set up a theoretical trade model in which a free trade agreement is used as a credible commitment by exporters of pollutionintensive goods. These exporters have a strategic advantage in a non-cooperative game of emissions. In this sense, they have an incentive to form a coalition and lobby their respective governments to secure a trade agreement prior to negotiating an international emissions agreement among trade members. Therefore, in this instance, a strategic trade policy follows the race to the bottom hypothesis.

Overall, our empirical findings are consistent with the results of theoretical models that find that strategic trade policies can create either the race to the bottom or race to the top hypothesis. For example, Bhattacharya and Pal (2010) develop a game-theoretical approach in which different trade regimes force countries to strategically choose their environmental standards. They find that lower trade barriers support race to the top hypothesis, consistent with our empirical findings for $\mathrm{CH}_{4}$, $\mathrm{HFCs} / \mathrm{PFCs} / \mathrm{SF}_{6}, \mathrm{~N}_{2} \mathrm{O}, \mathrm{NH}_{3}$, and $\mathrm{SF}_{6}$ (race to the bottom hypothesis consistent with our empirical findings for $\mathrm{SO}_{2}$ and municipal waste) when the domestic environmental strategic effect from local pollution dominates (is dominated by) the strategic environmental global effect owing to the freeriding incentives and the strategic effect due to international rent shifting.

Our empirical results suggest that lower trade barriers between the US and the EU may increase per capita emissions of $\mathrm{SO}_{2}$ and municipal waste. In addition, following the results of the theoretical work of Copeland and Taylor (1995), who suggest that exporters of pollution- intensive goods would like to secure a free-trade agreement prior to negotiating an international emission agreement, we suggest that officials on both sides of the Atlantic concentrate more effort on analyzing the potential harmful effects of the implementation of TTIP by these two pollutants. It might be better to include international emission agreements (in the chapter entitled "Raw Materials and Energy" of the potential TTIP) that set a target emission level or a percentage cut in emissions rather than a constant cut in emission (see Açıkgöz and Benchekroun (2017)). Further, it could be a better environmental policy to sign an international emission agreement before signing a trade deal (see Benchekroun and Yildiz (2011)).

For the average TTIP member, we find robust empirical evidence in support of Pollution Haven Hypothesis One and Two. In particular, on average, we find statistically significant evidence suggesting 
that per capita emissions of $\mathrm{CH}_{4}, \mathrm{~N}_{2} \mathrm{O}, \mathrm{SF}_{6}, \mathrm{SO}_{2}, \mathrm{SO}_{\mathrm{x}}$, and $\mathrm{NH}_{3}$ go up, as $\mathrm{EU}$ members get poorer, relative to the US, owing to the implementation of TTIP. This result is consistent with other recent empirical studies that provide evidence of Pollution Haven Hypothesis One in the presence of trade agreements (i.e., Cole \& Fredriksson, 2009; Kellenberg, 2009; Levinson \& Taylor, 2008; Taylor, 2005). Furthermore, we report robust empirical evidence suggesting that less densely populated countries act as pollution havens (following Pollution Haven Hypothesis Two) owing to the implementation of TTIP in the case of $\mathrm{HFCs} / \mathrm{PFCs} / \mathrm{SF}_{6}, \mathrm{~N}_{2} \mathrm{O}, \mathrm{CH}_{4}, \mathrm{SF}_{6}, \mathrm{SO}_{2}$, municipal waste, and $\mathrm{NH}_{3}$, respectively. We also find statistically significant evidence in support of the factor endowment hypothesis, suggesting that, on average and under the assumption that capital-intensive goods are considered pollutionintensive goods [for a theoretical basis on factor endowment hypothesis (see Antweiler et al. (2001)], an EU member with a lower capital to labor ratio, relative to the US, will see per capita emissions of $\mathrm{CH}_{4}, \mathrm{~N}_{2} \mathrm{O}, \mathrm{NH}_{3}$, and $\mathrm{SF}_{6}$, fall in response to the implementation of TTIP [see Qirjo and Christopherson (2016) for an empirical analysis of the implementation of TTIP under the factor endowment hypothesis and Pollution Haven Hypothesis One, but in the absence of Pollution Haven Hypothesis Two].

We also find statistically significant evidence suggesting that the implementation of TTIP in countries that use English as an official language may increase per capita emissions of $\mathrm{N}_{2} \mathrm{O}, \mathrm{HFCs} /$ PFCs/ $\mathrm{SF}_{6}, \mathrm{CH}_{4}, \mathrm{SF}_{6}, \mathrm{SO}_{\mathrm{x}}, \mathrm{NO}_{\mathrm{x}}$, and $\mathrm{NH}_{3}$ relative to non-English speaking countries. In the case of $\mathrm{CH}_{4}, \mathrm{HFCs} / \mathrm{PFCs} / \mathrm{SF}_{6}, \mathrm{~N}_{2} \mathrm{O}, \mathrm{NH}_{3}$, and $\mathrm{SF}_{6}$, this result could be because per capita emissions of the latter five air pollutants were reduced more in the former communist members of the EU, which produce more labor-intensive goods owing to higher trade intensity with the US.

Our results show that the implementation of TTIP in countries with sea or ocean access may help reduce per capita emissions of $\mathrm{CH}_{4}, \mathrm{NH}_{3}, \mathrm{HFCs} / \mathrm{PFCs} / \mathrm{SF}_{6}$, and $\mathrm{N}_{2} \mathrm{O}$ relative to landlocked countries. This result holds for these four air pollutants because EU members with sea access trade more with the US than landlocked EU members do.

We also report robust evidence indicating that the implementation of TTIP in countries that have adopted the Euro as their official currency may increase (decrease) per capita emissions of $\mathrm{SO}_{2}$, municipal waste, and $\mathrm{SO}_{\mathrm{x}}\left(\mathrm{SF}_{6}, \mathrm{NH}_{3}\right.$, and $\left.\mathrm{N}_{2} \mathrm{O}\right)$ compared with non-Euro TTIP members. In the cases of $\mathrm{SO}_{2}$ and municipal waste $\left(\mathrm{SF}_{6}, \mathrm{NH}_{3}\right.$, and $\left.\mathrm{N}_{2} \mathrm{O}\right)$, this result stands because Euro members trade more with the US owing to lower transaction costs, and, therefore, more trade between the Euro members and the US is associated with higher (lower) per capita emissions of $\mathrm{SO}_{2}$ and municipal waste $\left(\mathrm{SF}_{6}, \mathrm{NH}_{3}\right.$, and $\left.\mathrm{N}_{2} \mathrm{O}\right)$, respectively.

The remainder of this paper is organized as follows. Section 2 reviews the literature, section 3 describes our dataset and its sources, section 4 analyzes our models, section 5 discusses the empirical results, and section 6 presents the conclusions. 


\section{Literature Review}

There is a large and growing body of literature at the intersection of international trade and environmental economics. The literature can be categorized into three main groups: One addresses the effects of international trade on the environment, one focuses on the role of environmental rules and regulations on international trade, and another emphasizes the role of strategic trade policy on the environment and/ or the role of strategic environmental policies on international trade.

In this section, we briefly summarize these three branches of the literature and discuss them with regard to the empirical results found in this study.

From the appearance of the first major trade agreement in North America (North American Free Trade Agreement), there is a plethora of theoretical and empirical studies that analyze the effects of international trade on the environment. The majority of the leading theoretical papers in this literature (see Antweiler et al. (2001)) as an influential paper and also Copeland and Taylor (2005) for a comprehensive review on this literature] have concluded that international trade has ambiguous effects on pollution. In other words, free trade agreements can create either a race to the top hypothesis or race to the bottom hypothesis in terms of environmental consequences for trade members.4)

This study combined factor endowment hypothesis and Pollution Haven Hypothesis One. The factor endowment hypothesis follows the classical Heckscher-Ohlin theory that capital-abundant countries export capital-intensive goods, while labor-abundant countries export labor-intensive goods. The empirical literature supporting the factor endowment hypothesis finds evidence suggesting that capital-intensive goods pollute the environment more than labor-intensive goods. In other words, it classifies capital-intensive goods as pollution-intensive goods and labor-intensive goods

4) In addition to the above literature, there have been many recent theoretical and empirical works analyzing the effect of trade on the environment by employing increasing return à la Melitz (2003). The majority of the papers reveal theoretical and empirical results consistent with the race to the top hypothesis, thus concluding that free trade reduces pollution. The main argument in support of these findings lies in the idea that lower trade barriers will prioritize the most efficient firms [the ones that can afford foreign direct investment (FDI) and/ or to export] compared with the less efficient firms [the ones with no FDI and/ or to export], which would contract or go out of the market. As the most efficient firms are assumed to employ more environmentally friendly technologies (because they can afford it), then free trade would decrease pollution, as the less efficient firms (more pollutionintensive firms) would contract or go out of the market. Thus, the pollution related to international trade and/or FDI would decrease in all trade members [see Benarroch and Weder (2006) and Kreickemeier and Richter (2014) for papers that support the latter argument. See also Cherniwchan et al. (2017) for a comprehensive review of this literature]. Further, there is a vast body of literature that discusses the effect of trade on the pollution of non-trade treaty member developing countries owing to a potential trade agreement. This literature argues that international trade may indeed harm sub-global trade agreements (such as TTIP) in their attempts to lower pollution. Thus, sub-global trade members lower pollution among themselves at the expense of other developing non-member countries. This is because a trade agreement may create incentives for the pollution-intensive activities of the trade members to shift into the poor non-member countries. This is known as the carbon leakage literature. Markusen (1975) and Copeland's (1996) are two influential papers that suggest that domestic countries can use trade policies to avoid carbon leakage issues. Markusen (1975) introduces a simple import tax and Copeland (1996) introduces a pollution content tax on imports to fight carbon leakages. Winchester et al. (2011) show that carbon border adjustments could reduce leakage by up to two thirds. More recently, McAusland and Najjar (2015) study the existence of carbon footprint taxes to fight carbon leakage. 
as environmentally friendly goods (i.e., Cole \& Elliott, 2003; Davis \& Caldeira, 2010). Hence, the factor endowment hypothesis following the Heckscher-Ohlin theory suggests that a reduction in trade barriers would increase pollution in capital-abundant countries and decrease pollution in laborabundant countries. However, simultaneously with factor endowment hypothesis, we have Pollution Haven Hypothesis One, when countries lower their trade restrictions. Pollution Haven Hypothesis One claims that, under free trade, rich countries would strengthen their environmental standards, while poor countries would weaken their environmental standards because environmental quality is considered a luxury good. Hence, lower trade barriers, according to Pollution Haven Hypothesis One, would decrease pollution in rich countries, but increase it in poor countries (for empirical evidence that follows Pollution Haven Hypothesis One (see Cole \& Fredriksson, 2009; Levinson \& Taylor, 2008; Taylor, 2005).

Therefore, by combining the factor endowment hypothesis and Pollution Haven Hypothesis One, we cannot determine theoretically if free trade would follow a race to the top hypothesis or race to the bottom hypothesis [i.e., in our study, a typical EU member is labor-abundant but poorer than the US; hence, the possible implementation of TTIP would decrease (increase) pollution in the typical EU member (the US) according to factor endowment hypothesis, but would increase (decrease) pollution in the typical EU member (the US) following Pollution Haven Hypothesis One].

Following this literature, we provide some evidence suggesting that the implementation of TTIP would follow race to the top hypothesis for $\mathrm{CH}_{4}, \mathrm{~N}_{2} \mathrm{O}, \mathrm{NH}_{3}$, and $\mathrm{SF}_{6}$ because Pollution Haven Hypothesis One is dominated by the factor endowment hypothesis for an average TTIP member (see the results in Tables 4-12 under M1). However, we report statistically significant evidence suggesting that a trade deal between the US and the EU would follow the race to the bottom hypothesis for $\mathrm{SO}_{2}$ and municipal waste. In the case of $\mathrm{SO}_{2}$, Pollution Haven Hypothesis One dominated Pollution Haven Hypothesis Two.

The literature that emphasizes the role of environmental policy changes in international trade has received increased attention since the early $90 \mathrm{~s}$. The majority of the literature focuses on the role of carbon tax on global trade. Whalley and Wigle (1991) is one of the earlier influential papers in this literature. Abrego et al. (2001) provide a theoretical framework linking the bargaining strategies of environmental policies of developing countries when trading with developed countries. They show that developing countries can offer environmental concessions to accomplish trade agreements in developed countries. Carbone, Helm, and Rutherford (2009) develop a calibrated general equilibrium model in which countries consider strategic incentives when joining a trade agreement. They find that emission trade agreements between a small group of developed and developing countries are more likely to support the race to the top hypothesis than emission trade agreements with a large number of members. This empirical study considers the effects of international trade agreements on the environment.

To avoid the potential endogeneity between each pollutant and trade, we use a set of instrumental 
variable approaches.5) Further, we use a weighted lagged income variable to avoid any potential dual causality issues between each of our pollutants and per capita income, known as the Porter hypothesis (for a recent contribution on the Porter hypothesis (see Cohen \& Tubb, 2018).

From the pioneering work of Brander and Spencer (1985), who apply an export subsidy model to analyze strategic trade policies in firms with market power, there have been many similar applications exploring strategic environmental policies on international trade. For example, Conrad (1993), Barrett (1994), and Markusen et al. (1995) laid the theoretical foundations of the role of strategic environmental policies on international trade.

The main point of much of this literature is that environmental policy affects trade and FDI flows, where stringent environmental policies could be aimed at driving away polluting firms (race to the top hypothesis). Weak environmental policies, in order to fight foreign competition, could be used to increase domestic production (race to the bottom hypothesis). Markusen et al. (1995) show that small changes in environmental policies may cause large changes in pollution, as firms choose to relocate. In this sense, the government may engage in either the race to the top hypothesis (when they strengthen their environmental regulations) or race to the bottom hypothesis (when their environmental standards are lower).

Using a game-theoretical approach, Barrett (1994) shows that governments have incentives to engage in race to the bottom hypothesis by imposing weak environmental standards (to improve their competitiveness in foreign markets). Conrad (1993) also employs a game-theoretical approach and shows that the government has incentives to engage in race to the top hypothesis by introducing subsidies for cleaner technologies and products.6) Fujiwara (2010), using a reciprocal market model of duopoly with transboundary pollution, shows that strategic environmental policies could support race to the top hypothesis under lower import tariffs (or lower transportation costs). Benchekroun and Yildiz (2011) employ a behavior model to analyze the role of free trade in the sustainability of international environmental agreements (IEA). Among other things, they find that the IEA could be more sustainable under higher tariffs rather than lower tariffs. Açıkgöz and Benchekroun (2017) show that an IEA that sets a target emission level or a percentage cut in emission policy performs better than an IEA that sets a constant cut in emission policy.

In recent years, there has been much interest in the role of strategic trade policy in the environment. The key promise of much work in this area is that strategic trade policies (changes in trade regimes and/or joining a sub-global trade agreement) affect the strategic interaction among governments in their choice of environmental policy. Copeland and Taylor (1995) develop a theoretical model in which a free trade agreement is used as a credible commitment by exporters of pollution-

5) Such as instrumenting our main trade variable and its covariates with their respective lagged variables, or instrumenting trade with a set of exogenous variables, such as exchange rates, price of exports and imports, and capital to labor ratio.

6) See also Levinson and Taylor (2008), Levinson (2009), and Levinson (2010) for recent empirical evidence on the effect of environmental policies on trade flows. 
intensive goods. These exporters have a strategic advantage in the non-cooperative game of emissions. In this sense, they have an incentive to form a coalition and lobby their respective governments to secure a trade agreement prior to negotiating an international emissions agreement. Therefore, in this instance, a strategic trade policy follows race to the bottom hypothesis. Our empirical study provides evidence for $\mathrm{SO}_{2}$ and municipal waste that confirms race to the bottom hypothesis, as we find that more trade between EU members and the US increases per capita emissions of these pollutants in a typical TTIP member.

Bommer and Schulze (1999) design a theoretical model with a politically endogenous (independent of the trade regime) environmental policy and show that trade liberalization supports race to the top hypothesis. Burguet and Sempere (2003) apply a theoretical framework similar to Brander and Spencer (1985), who show how strategic trade distortions in environmental policies change in the face of trade reduction in a two-country world. They conclude that lower trade barriers tend to reduce the incentives to increase the pollution associated with trade in both countries. Lai and $\mathrm{Hu}(2008)$ set up a strategic trade model to analyze the potential of trade agreements to increase global welfare when domestic environmental policies are not feasible. They find that tariff reduction by all members is beneficial to the global environment. The empirical findings of our study for $\mathrm{CH}_{4}, \mathrm{HFCs} / \mathrm{PFCs} / \mathrm{SF}_{6}, \mathrm{~N}_{2} \mathrm{O}, \mathrm{NH}_{3}$, and $\mathrm{SF}_{6}$ confirm the main conclusions of Bommer and Schulze (1999), Burguet and Sempere (2003), and Lai and $\mathrm{Hu}$ (2008), as we report that higher trade intensity (i.e., when countries impose lower trade barriers) between EU members and the US decreases per capita emissions of these two pollutants in a typical TTIP member.

Other studies [i.e., Benarroch \& Weder (2006); Bhattacharya \& Pal (2010); Nkuiya (2013)] developed theoretical models that find that strategic trade policies can create either race to the bottom hypothesis or race to the top hypothesis.7) Using an intra-industry trade model with intermediate inputs, Benarroch and Weder (2006) show that freer trade may create race to the bottom hypothesis when there exists a constant return to the pollution function (pessimistic scenario). However, trade liberalization always supports a race to the top hypothesis under increasing returns to scale pollution function (optimistic scenario). Following this line of thought, our empirical results support the optimistic scenario for $\mathrm{CH}_{4}, \mathrm{HFCs} / \mathrm{PFCs} / \mathrm{SF}_{6}, \mathrm{~N}_{2} \mathrm{O}, \mathrm{NH}_{3}$, and $\mathrm{SF}_{6}$, while supporting the pessimistic scenario for $\mathrm{SO}_{2}$ and municipal waste. Bhattacharya and Pal (2010) develop a game- theoretical approach in which different trade regimes force countries to strategically choose their environmental standards. They find that lower trade barriers support race to the top hypothesis, consistent with our empirical findings for $\mathrm{CH}_{4}, \mathrm{HFCs} / \mathrm{PFCs} / \mathrm{SF}_{6}, \mathrm{~N}_{2} \mathrm{O}, \mathrm{NH}_{3}$, and $\mathrm{SF}_{6}$ (race to the bottom hypothesis consistent

7) More recently, there have also been theoretical empirical studies that simultaneously analyze the strategic impact of trade liberalization on environmental policies and the strategic effect of environmental policies on the international trade regime. For example, Finus and Al Khourdajie (2018) add an agreement formation structure to a "love of variety" approach with a strategic trade and strategic environmental policies model. Their key finding implies that only with sufficiently high taste for variety can strategic interactions among treaty members fall in order to stabilize agreements with a short group of countries. Kellenberg (2009) finds empirical evidence in support of Pollution Haven Hypothesis One using cross-country data when controlling for strategically determined environment, trade, and intellectual property right policies. 
with our empirical findings for $\mathrm{SO}_{2}$ and municipal waste) when the domestic environmental strategic effect owing to local pollution dominates (is dominated by) the strategic environmental global effect owing to the free-riding incentives and the strategic effect due to international rent shifting.

Nkuiya (2013) developed an oligopolistic trade game and analyzed the possible improvement in domestic environmental protection or the dilution of environmental standards when asymmetric countries join a multi-national trade agreement. He shows that trade liberalization follows a trade to the top argument in large members because it increases output production, and, therefore, decreases the price of goods, but it increases the marginal environmental damage associated with production. Thus, it forces large treaty members to raise their environmental standards. However, the inverse occurs in small trade members, where the reduction of multilateral tariffs reduces government revenues from tariffs and decreases the costs of exports. Therefore, smaller members weaken their environmental standards following race to the bottom hypothesis. If free trade improves the environment, it depends on the magnitude of the pollution decrease in large members compared with the pollution increase in small members.

\section{Description of Pollutants and Data Sources}

We denote methane by $\mathrm{CH}_{4}$ and obtained data for $\mathrm{CH}_{4}$ from CAIT (2019). Data for methane are expressed in kilograms $(\mathrm{kg})$ of $\mathrm{CO}_{2}$ equivalent $\left(\mathrm{KGCO}_{2} \mathrm{e}\right)$ per capita emissions. According to the United States Environmental Protection Agency (2020) and European Environment Agency (2019), methane is the second most prevalent GHG originating from human activities emitted in the US. In the last decade, $\mathrm{CH}_{4}$ accounted for approximately $10 \%$ of the US and the EU's GHG emissions from human activities. The main sources of $\mathrm{CH}_{4}$ from human activities originate from raising livestock and leakage from natural gas systems. Although the lifetime of $\mathrm{CH}_{4}$ in the atmosphere is much shorter than that of $\mathrm{CO}_{2}$, the comparative effect of $\mathrm{CH}_{4}$ on climate change is 25 times greater than that $\mathrm{CO}_{2}$ over a 100 years period.

Nitrous oxide is denoted as $\mathrm{N}_{2} \mathrm{O}$. We obtained $\mathrm{N}_{2} \mathrm{O}$ data from the United Nations Framework Convention on Climate Change (UNFCCC) (2019). Data for nitrous oxide are expressed in kilograms $(\mathrm{kg})$ of $\mathrm{CO}_{2}$ equivalent $\left(\mathrm{KGCO}_{2} \mathrm{e}\right)$ per capita emissions. In the last decade, $\mathrm{N}_{2} \mathrm{O}$ accounted for approximately $7 \%$ of all the US and the EU's GHGs, originating from human activities. United States Environmental Protection Agency (2020) and European Environment Agency (2019) concluded that almost three-fourths of anthropogenic $\mathrm{N}_{2} \mathrm{O}$ comes from agricultural soil management. Other sources of anthropogenic $\mathrm{N}_{2} \mathrm{O}$ include waste, fuel combustion, and industrial activities (where $\mathrm{N}_{2} \mathrm{O}$ is generated as a byproduct during the production of certain chemicals).

We denote sulfur hexafluoride as $S F_{6}$, and obtained per capita emissions of $\mathrm{SF}_{6}$ from UNFCCC 
(2019), that is, Ton in $\mathrm{CO}_{2}$ equivalent $\left(\mathrm{TCO}_{2} \mathrm{e}\right)$ per capita emissions. According to the Intergovernmental Panel on Climate Change (2014), $\mathrm{SF}_{6}$ is the most potent gas of all GHGs. The impact of $\mathrm{SF}_{6}$ on climate change is approximately 2300 times greater than that of $\mathrm{CO}_{2}$ over the past 100 years and is extremely long-lived in the atmosphere. However, according to the Intergovernmental Panel on Climate Change (2014), despite being the most potent GHG, its contribution to global warming is estimated to be less than $0.02 \%$. This is due to the very low release of $\mathrm{SF}_{6}$ into the atmosphere compared with that of $\mathrm{CO}_{2}$. According to the United States Environmental Protection Agency (2020), emissions of $\mathrm{SF}_{6}$ in the US have declined since 1990 owing to reduction efforts of the electricity transmission and distribution industry.

We denote hydrofluorocarbons as $H F C$ and perfluorocarbons as PFC. These GHGs, together with $\mathrm{SF}_{6}$ and ammonia $\left(\mathrm{NH}_{3}\right)$, are called fluorinated gases or simply F-gases. United States Environmental Protection Agency (2020) states that, "unlike many other greenhouse gases, fluorinated gases have no natural sources and only come from human-related activities. Many fluorinated gases have very high global warming potentials relative to other greenhouse gases, so small atmospheric concentrations can have large effects on global temperatures. They can also have long atmospheric lifetimes, in some cases, lasting thousands of years." According to the United States Environmental Protection Agency (2020) and European Environment Agency (2019), HFCs are used as refrigerant aerosol propellants, solvents, and fire retardants. The major emission sources of these compounds are their use as refrigerants or in air conditioning systems in both vehicles and buildings. PFCs are compounds produced as byproducts of various industrial processes associated with aluminum production and semiconductor manufacturing. In the US, between 1990 and 2015, emissions of HFCs increased by $250 \%$ owing to their wide use as a substitute for ozone-depleting substances. However, during the same time period, emissions of PFCs declined owing to emission reduction efforts in the aluminum production industry. We have aggregate data for per capita emissions of $\mathrm{HFCs}$, PFCs, and $\mathrm{SF}_{6}$, but not for $\mathrm{NH}_{3}$. Data were obtained from the UNFCCC (2019) and are in kilograms (kg) in $\mathrm{CO}_{2}$ equivalent $\left(\mathrm{KGCO}_{2} \mathrm{e}\right)$ per capita emissions.

Our models denote sulfur oxides, sulfur dioxide, and nitrogen oxide as $\mathrm{SO}_{x}, \mathrm{SO}_{2}$, and $\mathrm{NO}_{x}$, respectively. We obtained data for these pollutants from the following sources: $\mathrm{SO}_{2}$ data are based on Stern (2006), the Convention on Long-Range Transboundary Air Pollution (LRTAP) (2020), and the National Emission Ceilings Directive and National Financial Regulation (NECNFR) (2020). $\mathrm{SO}_{\mathrm{x}}$ data are from the European Environment Agency (2019) and LRTAP (2020). $\mathrm{NO}_{\mathrm{x}}$ data were obtained from LRTAP (2020) and NECNFR (2020). SOx is measured in gigagrams $(\mathrm{Gg})$ emissions per capita, while $\mathrm{SO}_{2}$ is measured in grams (g) emissions per capita, and $\mathrm{NO}_{\mathrm{x}}$ is measured in metric ton (Mt) emissions per capita. These pollutants are released into the atmosphere as byproducts of the energy transformation process when converting fossil fuels to energy. In the air, these substances are turned into acidifying agents, often called acid rain; and on the ground, these pollutants cause both soil and water acidification. United States Environmental Protection Agency (2020) and European Environment Agency (2019) 
reported that, over the past 25 years, there has been a decline in all the above air pollutant emissions, for several reasons: a switch to more non-fossil fuel energy sources, energy conservation and recycling, technological improvements, and stronger environmental regulations. However, this improvement seen in the US and EU members has been offset in some other parts of the world, where economic and industrial growth has resulted in increased fossil fuel use.

Table 1. Data Sources of Pollutants and their Unit of Measurement

\begin{tabular}{|c|c|c|}
\hline Variable & Source & Unit of Measurement \\
\hline $\mathrm{CH}_{4}$ (Methane) & CAIT (2019) & $\mathrm{Kg}$ in $\mathrm{CO} 2$ equiv. per capita \\
\hline $\mathrm{HFCs} / \mathrm{PFCs} / \mathrm{SF}_{6}$ (F-Gases) & UNFCCC (2019) & $\mathrm{Kg}$ in $\mathrm{CO} 2$ equiv. per capita \\
\hline $\mathrm{NH}_{3}$ (Ammonia) & LRTAP (2020) \& NECNFR (2020) & Mt per capita \\
\hline $\mathrm{N}_{2} \mathrm{O}$ (Nitrous Oxide) & UNFCCC (2019) & $\mathrm{Kg}$ in $\mathrm{CO} 2$ equiv. per capita \\
\hline$N O_{x}$ (Nitrogen Oxide) & LRTAP (2020) \& NECNFR (2020) & Mt per capita \\
\hline$S F_{6}$ (Sulfur Hexafluoride) & UNFCCC (2019) & $\mathrm{T}$ in $\mathrm{CO} 2$ equiv. per capita \\
\hline $\mathrm{SO}_{2}$ (Sulfur Dioxide) & Stern (2006), LRTAP (2020) \& NECNFR (2020) & Gm per capita \\
\hline$S O_{x}$ (Sulfur Oxide) & EEA (2019) \& LRTAP (2020) & Gg per capita \\
\hline$M W$ (Municipal Waste) & EUROSTAT (2020) \& OECD (2020) & Kg per capita \\
\hline $\begin{array}{l}T \text { (Trade Intensity, Volume of } \\
\text { Trade/ GDP) }\end{array}$ & IMF (2021) & Percentage $(0-100)$ \\
\hline$I$ (Real GDP per capita) & IMF (2021) & Real (2017) U.S. Dollars \\
\hline KL (Capital to Labor Ratios) & PWT (2021) & Real (2017) PPPs U.S. Dollars \\
\hline $\begin{array}{l}\text { LPC (Log of Land area per } \\
\text { capita) }\end{array}$ & CIA (2021) & Log of $\mathrm{Km}^{2}$ per capita \\
\hline FDI (FDI Stock/Capital Stock) & IMF (2021) & Percentage $(0-100)$ \\
\hline $\begin{array}{l}\{T(\text { English Dummy) }\} \text { (Dummy } \\
\text { for Language) }\end{array}$ & CIA (2021) & Percentage $(0-100]=$ English, $0=$ otherwise \\
\hline $\begin{array}{l}\{T(\text { Sea Dummy })\} \text { (Dummy for } \\
\text { Landlocked) }\end{array}$ & CIA (2021) & Percentage $(0-100]=$ access to sea, $0=$ otherwise \\
\hline $\begin{array}{l}\{T(\text { Euro Dummy })\} \text { (Dummy } \\
\text { for Euro) }\end{array}$ & EUROSTAT (2020) & Percentage $(0-100]=$ using Euro, $0=$ otherwise \\
\hline
\end{tabular}

We denote ammonia as $\mathrm{NH}_{3}$ and obtained per capita emissions of NH3 from LRTAP (2020) and NECNFR (2020), which are in metric ton (Mt) emissions per capita. $\mathrm{NH}_{3}$ is a gas that is mainly released into the atmosphere from the decay process of nitrogenous animal and vegetable matter.

Municipal solid waste is denoted as $M W$. Both United States Environmental Protection Agency (2020) and European Environment Agency (2019) define municipal waste as the waste collected and treated by or for municipalities. It covers waste from appliances, batteries, bottles, cans, clothing, food scraps, furniture, grass clippings, product packaging, newspaper paint, and plastic materials. Municipal waste is generated from households, houses, hospitals, schools, government enterprises, and private businesses. United States Environmental Protection Agency (2020) summarized that, in 
2018, Americans generated approximately 292 million tons of trash and recycled and composted almost 94 million tons of this material, equivalent to a $32.1 \%$ recycling rate. Data for municipal waste comes from Eurostat (2020) and OECD (2020) in kilogram (kg) of municipal waste generated per capita as a unit of measurement for this pollutant.

In Table 2, we provide a statistical description of these variables along with the results of the unit root test by Im et al. (2003). All variables are stationary after controlling for a deterministic time trend, with the exception of $\mathrm{CH}_{4}, L P C, R I, R L P C$, and $R K L$. For the latter five variables, we perform the Harris-Tzavalis unit root test, where each of these five variables is also found to be stationary around a deterministic time trend. Note that the data for all variables are over the 1990-2018 time period for 27 EU members and the US. All the other variables are as in Qirjo and Pascalau (2019b). It is worth noting here that all value-based data use 2017 as a base year expressed in US\$ [also note that (Qirjo \& Pascalau , 2019b) use 2005 as a base year] ${ }^{8)}$

\section{Econometric Models}

This section discusses the economics of the three econometric models used in this study.

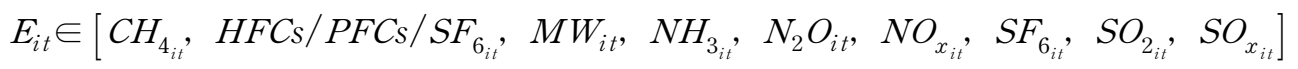
denotes the per capita emissions of each of the above nine pollutants. These are the dependent variables. Note that $\theta_{i}, \xi_{t}$, and $\epsilon_{i t}$ denote the TTIP member-specific constant term, the timespecific constant term, and the idiosyncratic measurement error term, respectively, where $t$ and $i$ denote the period 1990-2018 and TTIP member (28 members), respectively.

Model one (M1) investigates the effect of further trade between the US and the EU in the presence of the factor endowment hypothesis, Pollution Haven Hypothesis One, and our control variables. The trade intensity term, denoted by $T_{i t}$, is the sum of bilateral exports and imports between each EU member and the US over GDP. The factor endowment hypothesis is measured by the product of the trade intensity variable and the capital to labor ratio relative to the US [denoted by $T(R K L)_{i t}$ ] along with its squared term $T(R K L)_{i t}^{2}$ to account for diminishing returns. Pollution Haven Hypothesis One is measured by the product of the trade intensity variable and per capita income relative to the US, denoted by $T(R I)_{i t}$, along with its squared term $T(R I)_{i t}^{2}$, to account for diminishing returns. The control variables are denoted as $Z_{i t}$. They include the scale and technique effects (denoted by $I_{i t}$ and $I_{i t}^{2}$, respectively, in order to evaluate the existence of the environmental Kuznets curve (EKC). In addition, they include the product of income per capita and the capital to labor ratio, denoted by $I(K L)_{i t}$, to capture the direct composition of growth, and the capital to

8) See also Pascalau and Qirjo (2017a) for details on filling out the missing observations using the Amelia 2 program in $R$. 
labor ratio, denoted by $(K L)_{i t}$, along with its squared term $(K L)_{i t}^{2}$, to account for diminishing returns, to measure the general composition of growth.

$$
\begin{gathered}
E_{i t}=\theta_{i}+\xi_{t}+\alpha_{1} T_{i t}+\alpha_{2} T_{i t}(R K L)_{i t}+\alpha_{3} T_{i t}(R K L)_{i t}^{2} \\
+\alpha_{4} T_{i t}(R I)_{i t}+\alpha_{5} T_{i t}(R I)_{i t}^{2}+\beta_{j} Z_{i t}+\epsilon_{i t}
\end{gathered}
$$

In M1, the statistical significance of the coefficient $\alpha_{1}$ captures the effect of trade between the US and the EU on pollution. If positive and statistically significant, this implies that more trade between the EU and the US would lead to higher pollution. This is known in environmental economics literature as race to the bottom hypothesis. Under this hypothesis, members of a trade treaty lower their environmental standards to decrease their production costs to increase exports. However, if $\alpha_{1}$ is negative and statistically significant, further trade between the US and the EU translates to lower pollution. This is known as the race to the top hypothesis, where trade members increase their environmental standards along with their volume of trade. This may happen for several reasons: 1) increased awareness of the population to the negative impacts of pollution, which forces policymakers of all treaty members to strengthen environmental laws and regulations; 2) the efficiency of the transfer of environmentally friendly technologies among treaty members; and 3) the economic development of all members ( especially the poorest ones) owing to higher trade volumes, which may also result in increasing environmental standards for all treaty members.

The factor endowment hypothesis is evaluated using the coefficients $\alpha_{2}$ and $\alpha_{3}$. In our dataset, a typical EU member is labor-abundant relative to the US. Therefore, following the HeckscherOhlin trade theory, we expect that the implementation of TTIP would lead to more production of capital-intensive goods (which are considered more pollution-intensive goods than laborintensive goods) in the US and more labor-intensive goods in an average EU member. However, the latter is not true for all EU members. In our dataset, there are eleven EU members that have a higher capital to labor ratio than the US, namely, Austria, Belgium, Cyprus, Finland, France, Greece, Ireland, Italy, Luxembourg, Spain, and Sweden. For more details, see the middle column of Table 3. Thus, more trade between these EU members and the US would theoretically increase exports of capital-intensive goods from the latter eleven EU members to the US, and also increase their imports of labor-intensive goods from the US. In other words, the implementation of TTIP, according to factor endowment hypothesis, would decrease pollution in the US, but increase pollution in each of the latter eleven EU members.

Pollution Haven Hypothesis One is captured by coefficients $\alpha_{4}$ and $\alpha_{5}$. In our dataset, an average EU member is poorer than the US. Consequently, more trade between the EU and the US could force an average EU member to act as a pollution haven according to Pollution Haven Hypothesis 
One. This is related to the theory that relatively environmentally friendly goods are considered luxury goods that only rich countries can afford. In other words, rich countries adopt stringent environmental laws and regulations compared with poor countries, and, therefore, further trade between a typical EU member and the US could force the latter to concentrate its production on environmentally friendly goods and import pollution-intensive goods from the average EU member. However, this is not the case for all EU members, as three EU members (Denmark, Luxembourg, and Sweden) are richer than the US (see the first column of Table 3). Thus, following Pollution Haven Hypothesis One, the implementation of TTIP could force the US to act as a pollution haven.

Combining factor endowment hypothesis and Pollution Haven Hypothesis One, it is impossible to predict theoretically if the implementation of TTIP follows race to the bottom hypothesis or race to the top hypothesis. This is related to the fact that an average TTIP member is labor-abundant and poorer than the US. Thus, further trade between the US and the EU would decrease pollution in a typical TTIP member following factor endowment hypothesis, and increase pollution in a typical TTIP member following Pollution Haven Hypothesis One. Consequently, if the implementation of TTIP supports the race to the bottom hypothesis or race to the top hypothesis is an empirical question. However, we can claim theoretically that more trade between the US and Denmark (labor-abundant and rich EU member as compared to the US) would decrease pollution in Denmark. This is because the implementation of TTIP should theoretically force Denmark to increase the exports of labor-intensive goods (environmentally friendly goods) to the US and strengthen its environmental laws and regulations, as Denmark is richer than the US. Analogously, more trade between the US and capital-abundant and poor EU members (Austria, Belgium, Cyprus, Finland, France, Greece, Ireland, Italy, and Spain) would decrease pollution in the US. This is because the implementation of TTIP should theoretically force these nine EU members to increase their exports of capital-intensive goods (pollution-intensive goods) to the US, and also act as pollution havens since they are poorer than the US.

$$
\begin{aligned}
E_{i t}= & \theta_{i}+\xi_{t}+\alpha_{1} T_{i t}+\alpha_{2} T_{i t}(R K L)_{i t}+\alpha_{3} T_{i t}(R K L)_{i t}^{2}+\alpha_{4} T_{i t}(R I)_{i t} \\
& +\alpha_{5} T_{i t}(R I)_{i t}^{2}+\alpha_{6} T_{i t}(R L P C)_{i t}+\alpha_{7} T_{i t}(R L P C)_{i t}^{2}+\beta_{j} Z_{i t}+\epsilon_{i t}
\end{aligned}
$$

In M2, in addition to all the variables included in M1, we added two variables associated with Pollution Haven Hypothesis Two. These are the product of the trade intensity variable and the relative to the US land per capita, denoted by $T_{i t}(R L P C)_{i t}$, along with its squared term $T_{i t}(R L P C)_{i t}^{2}$, to account for diminishing returns. In addition to the control variable included in M1, we add the land per capita variable along with its squared value. Moreover, we also 
include the ratio of inward FDI to the stock of physical capital in order to evaluate the classical pollution haven motive, which claims that multinational corporations relocate their most polluted activities to foreign countries with lax environmental regulations.

Pollution Haven Hypothesis Two is evaluated by the statistical significance of the coefficients $\alpha_{6}$ and $\alpha_{7}$. In the dataset, a typical EU member has less land per capita than the US. Consequently, more trade between the EU and the US could force the US to act as a pollution haven. This is supported by the work of Frankel and Rose (2005), who argue that densely populated countries adopt stringent environmental laws and regulations because land is scarce and protected more than sparsely populated countries blessed with an abundance of land. Hence, further trade between a typical EU member and the US could force the typical EU member to concentrate its production on environmentally friendly goods and import pollution-intensive goods from the US, which will act as a pollution haven. However, this is not the case for all the EU members. In our dataset, there are two EU members (Finland and Sweden) that are more sparsely populated than the US. For more details, see the last column of Table 3. Thus, according to Pollution Haven Hypothesis Two, the implementation of TTIP could force these two EU members to act as pollution havens.

$$
\begin{gathered}
E\left(Z_{i t}\right)=\theta_{i}+\xi_{t}+\alpha_{1} T_{i t}+\alpha_{2} T_{i t}(R K L)_{i t}+\alpha_{3} T_{i t}(R K L)_{i t}^{2}+\alpha_{4} T_{i t}(R I)_{i t}+\alpha_{5} T_{i t}(R I)_{i t}^{2} \\
+\alpha_{6} T_{i t}(R L P C)_{i t}+\alpha_{7} T_{i t}(R L P C)_{i t}^{2}+\alpha_{8} T_{i t}(\text { English Dummy })_{i t} \\
+\alpha_{9} T_{i t}(\text { Sea Dummy })_{i t}+\alpha_{10} T_{i t}(\text { Euro Dummy })_{i t}+\beta_{j} Z_{i t}+\epsilon_{i t}
\end{gathered}
$$

In M3, we add three dummy variables to evaluate the effects of even more trade on the environment, at least theoretically, between the US and some EU members. In particular, we claim that there is more trade between the US and EU members that use English as one of their official languages. In our dataset, there are only three countries that use English as an official language (Ireland, Malta, and the US). We also argue that the US may trade more with countries that have access to the sea and/or ocean compared to landlocked countries. In our dataset, there are only five TTIP members that are landlocked countries (Austria, Czech Republic, Hungary, Luxembourg, and Slovakia). Moreover, we claim that there is more trade between the US and the Eurozone members, as the latter EU members use the same currency (Euro) and there are lower currency exchange costs. In 2018, 19 EU members were part of the Eurozone.

We capture the effect on the environment from higher trade intensity between the US and English-speaking EU members by the product of the trade intensity variable and the English dummy variable, denoted by $T_{i t}(\text { English Dummy })_{i t}$. Here, we set 1 if a TTIP member uses English as one of its official languages and 0 otherwise. We measure the impact on the environment from more trade between the US and EU members that have sea and/ or ocean 
access by the product of the trade intensity variable and the sea dummy variable, denoted by $T_{i t}(\text { Sea Dummy })_{i t}$. Here, we use 1 if a TTIP member has access to the sea and/ or ocean and 0 otherwise. We capture the effect on the environment from further trade between the US and the Eurozone members by the product of the trade intensity variable and the Euro Dummy variable, denoted by $T_{i t}(\text { Euro Dummy })_{i t}$, where we set 1 for the years a TTIP member was a part of the Eurozone and 0 otherwise.

\section{Empirical Results}

We apply the same empirical methodology as in Qirjo and Pascalau (2019b). The effects of TTIP on HFCs/ PFCS/ $\mathrm{SF}_{6}, \mathrm{~N}_{2} \mathrm{O}, \mathrm{CH}_{4}, \mathrm{SO}_{2}, \mathrm{MW}, \mathrm{SO}_{x}, \mathrm{NO}_{x}, \mathrm{SF}_{6}, \mathrm{NH}_{3}$ per capita emissions, and $M W$ per capita are reported in Tables 4 through 12, respectively. Analogous to Qirjo and Pascalau (2019b), each table in this section reports the estimation results using fixed effects for M1, M2, and M3 in the first, second, and third columns, respectively, while the fourth, fifth, and sixth columns report the estimation results using random effects. Further, the seventh, eighth, and ninth columns report the results using cross-sectional fixed effects, while the tenth, eleventh and twelfth columns report the results using serial correlation fixed effects.

Scale-Technique Effects and the EKC. In all columns of Tables 4 through 12, we report the scale-technique effects. The sixth row indicates the proxy of the scale-technique effect, as measured by a one-period lagged three-year moving average of income per capita. In the seventh row, we report its squared value to investigate the empirical validity of the EKC. In the cases of $\mathrm{SF}_{6}, \mathrm{~N}_{2} \mathrm{O}$, and $\mathrm{NH}_{3}$, we provide some statistically significant evidence consistent with the EKC argument, which indicates that for low-income per capita values, there exists a positive relationship between per capita income and per capita emissions of $S F_{6}, N_{2} O$, and $\mathrm{NH}_{3}$, respectively, but for high income per capita values, there is a negative relationship between the latter two variables. In other words, initially for low levels of income per capita, the scale effect dominates the technique effect, but eventually, for high levels of income per capita, their role is reversed.9) Note that the empirical validity of the EKC is analyzed further in Pascalau and Qirjo (2017b) and Qirjo and Pascalau (2021), who employ a similar dataset as the current study, but they also control for the cube of income per capita variable and political economic

9) There is no statistically significant evidence that shows the empirical validity of EKC for the other pollutants. One could emphasize that, in the cases of $\mathrm{NO}_{\mathrm{x}}, \mathrm{SO}_{2}$, and $\mathrm{SO}_{\mathrm{x}}$, there is some statistically significant evidence of a positive and monotonic relationship between growth and per capita emissions of $\mathrm{NO}_{\mathrm{x}}, \mathrm{SO}_{2}$, and $\mathrm{SO}_{\mathrm{x}}$, respectively (although, for $\mathrm{SO}_{2}$ there is statistically significant evidence consistent to EKC only under M3 when employing the serial correlation fixed effects with Driscoll-Kraay robust standard errors). This implies that for these three air pollutants, the scale effect dominates the technique effect. 
variables such as the Gini coefficient, corruption measures, rule of law, contract enforcement, etc. They report empirical evidence in support of the EKC for $\mathrm{HFCs} / \mathrm{PFCs} / \mathrm{SF}_{6}, \mathrm{CH}_{4}$, and $\mathrm{CO}_{2}$, but they find a positive and monotonic relationship between per capita income and per capita emissions of GHGs, $\mathrm{SF}_{6}$, and $\mathrm{N}_{2} \mathrm{O}$, respectively. ${ }^{10}$ ) Composition Effects. We report the direct composition effect of growth, as measured by the capital-labor ratio, and the composition effect of growth, as measured by the cross product of income per capita and capital-labor ratio in the eighth and tenth rows, respectively, in Tables 4 through 12 . We also include the square of the capital-labor ratio, in the ninth row of our tables. To capture the diminishing effect of capital accumulation at the margin, we also include the square of the capital-labor ratio. We find that the accumulation of capital increases the per capita emissions of $\mathrm{CH}_{4}, \mathrm{~N}_{2} \mathrm{O}, \mathrm{NH}_{3}$, $\mathrm{NO}_{\mathrm{x}}$, and $\mathrm{SF}_{6}$. At the same time, we report that the accumulation of capital decreases per capita emissions of municipal waste and $\mathrm{HFCs} / \mathrm{PFCs} / \mathrm{SF}_{6}$. We also find a positive and statistically significant relationship between the composition of growth and per capita $\mathrm{SO}_{2}$ emissions. However, we show negative and statistically significant evidence between the composition of growth and per capita emissions of $\mathrm{CH}_{4}, \mathrm{HFCs} / \mathrm{PFCs} / \mathrm{SF}_{6}$, municipal waste, $\mathrm{N}_{2} \mathrm{O}, \mathrm{NO}_{\mathrm{x}}, \mathrm{SF}_{6}$, $\mathrm{SO}_{\mathrm{x}}$, and $\mathrm{NH}_{3}$, respectively. Population Density Effects. We report the relationship between an inverse measurement of population density, proxied by land per capita, and pollution in the fourteenth row, only for M2 and M3 under each estimation method in Tables 4-12. We also include its squared value in the fifteenth row to capture its diminishing returns. We provide negative (positive) and statistically significant evidence of population density (land per capita) and per capita emissions for all nine pollutants included in our dataset. FDI Effects. We show the effects of FDI (over the stock of capital) on pollution in the thirteenth row when using M2 and M3 for each estimation method in Tables 4 through 12. We report a statistically significant and positive relationship between FDI measurements and the per capita emissions of $\mathrm{CH}_{4}$, municipal waste, and $\mathrm{NO}_{x}$, respectively. This follows the classical Pollution Haven argument, which claims that multinational corporations locate their production in countries that have lax environmental regulations and policies.

However, we also report a statistically significant and negative relationship between the FDI variable and the per capita emissions of $\mathrm{HFCs} / \mathrm{PFCs} / \mathrm{SF}_{6}$. This negative relationship is consistent with the technique effect of FDI, which argues that multinational corporations spread out their environmentally cleaner production methods for quality control, or engineering from their countries of origin. Consequently, in this case, multinationals may reduce the per capita emissions of $\mathrm{HFCs} / \mathrm{PFCs} / \mathrm{SF}_{6}$.

10) In addition, using the same empirical specifications and models, but a dataset that contains the 28 EU members and Canada during the 1990-2016 time period, Qirjo et al. (2019), Qirjo et al. (2020), and Qirjo et al. (2021) investigate the existence of the EKC and find no evidence in its support for per capita emissions of GHGs and $\mathrm{CO}_{2}$. 
Factor Endowment Hypothesis. We use the cross-product of trade intensity and relative capital-to-labor ratio to capture the factor endowment hypothesis. This is denoted by $T(R K L)$, and it is reported in the second row of Tables 4 through 12. We present the squared term of the cross-product of trade and the relative capital to labor ratio (in order to measure diminishing returns) in the third row of Tables 4 through 12. Given that, as we are investigating the possible role of the implementation of TTIP on the environment, the relative capital-labor ratios are expressed relative to the US, and trade intensity is expressed as the ratio of the volume of bilateral trade of each EU member to the US divided by national GDP (in the case of the US, it is its total of exports and imports with all EU members divided by the GDP of the US); the factor endowment hypothesis suggests that the implementation of TTIP would increase pollution in capital-abundant countries and decrease it in labor-abundant countries. Following the literature on trade and the environment, capital-intensive goods are considered pollution intensive goods, while labor-intensive goods are considered environmentally friendly goods. Hence, following the classical Heckscher-Ohlin theory, further trade openness between the capital-abundant US and a typical labor-abundant EU member would increase the production of capital-intensive goods in the US, and labor-intensive goods in an average EU member. Note that there are only $11 \mathrm{EU}$ members that have a higher capital to labor ratio than the US, while all the other EU members have lower capital to labor ratios. Thus, higher trade intensity between the US and a typical EU could lead to higher pollution in the US and lower pollution in an average EU member. In our sample, on average, focusing on the signs of $T(R K L)$ and $T(R K L)^{2}$, we find statistically significant evidence consistent with the factor endowment hypothesis for $\mathrm{CH}_{4}, \mathrm{~N}_{2} \mathrm{O}, \mathrm{NH}_{3}$, and $\mathrm{SF}_{6}$, respectively. Moreover, we find statistically significant evidence implying a convex relationship between the product of trade and the relative capital to labor ratio and per capita emissions of $\mathrm{NO}_{\mathrm{x}}, \mathrm{SO}_{2}, \mathrm{SO}_{\mathrm{x}}$, and municipal waste, respectively. Pollution Haven Hypothesis One and Two. We employ the cross-product of trade intensity and relative income per capita to capture Pollution Haven Hypothesis One. This is denoted by $T(R I)$ and reported in the fourth row of Tables 4 through 12 . We report its squared value in the fifth row to capture diminishing returns. Note that income per capita is measured as the three-year lagged moving average of real GDP $\left(I_{i t}=.6^{*} I_{i t-1}+.3^{*} I_{i t-2}+.1^{*} I_{i t-3}\right)$.

In addition, as we are investigating the possible role of the implementation of TTIP in the environment, the relative income per capita of each country is expressed relative to the US Pollution Haven Hypothesis One claims that environmentally friendly goods are luxury goods. Here, poor countries are encouraged to adopt lax environmental regulations and policies, and, therefore, produce mainly pollution-intensive goods. Analogously, rich countries adopt stringent environmental regulations and policies that force them to produce environmentally cleaner goods. In our sample, only three EU members are richer than the US (Denmark, Luxembourg, and Sweden). Therefore, following Pollution Haven Hypothesis One, more trade between the US 
and the EU should decrease pollution in the US and increase pollution in a typical EU member.

On average, we found statistically significant evidence in support of Pollution Haven Hypothesis One for $\mathrm{CH}_{4}, \mathrm{~N}_{2} \mathrm{O}, \mathrm{SF}_{6}, \mathrm{SO}_{2}, \mathrm{SO}_{\mathrm{x}}$, and $\mathrm{NH}_{3}$. Thus, on average, the per capita emissions of these six air pollutants decrease as countries become richer owing to the implementation of TTIP. In other words, following Pollution Haven Hypothesis One, an EU member (which is poorer than the US, with the exception of Denmark, Luxembourg, and Sweden, which are all richer than the US) would act as a pollution haven, under lower trade barriers between the US and the EU, for the latter six air pollutants. In the case of municipal waste, we find statistically significant evidence implying a concave relationship between the product of trade and relative income per capita and per capita emissions of municipal waste.

We use the cross-product of trade intensity and relative land per capita to detect Pollution Haven Hypothesis Two. This is denoted by $T(R L P C)$, and it is reported in the eleventh row of Tables 4 through 12. We report its squared value in the twelfth row to measure diminishing returns. The relative land per capita of each country is expressed relative to the US Consistent with Pollution Haven Hypothesis Two, the implementation of TTIP may move the production of pollution-intensive goods from densely populated countries towards sparsely populated ones. In our sample, there are only two EU members that are more sparsely populated than the US (Finland and Sweden). All other EU members are more densely populated than the US. Thus, the less densely populated US may act as a pollution haven owing to the implementation of TTIP. We found statistically significant evidence in accordance with Pollution Haven Hypothesis Two for HFCs/ PFCs/ $\mathrm{SF}_{6}, \mathrm{~N}_{2} \mathrm{O}, \mathrm{CH}_{4}, \mathrm{SF}_{6}, \mathrm{SO}_{2}$, municipal waste, and $\mathrm{NH}_{3}$. In other words, there is a positive concave relationship between the relative land per capita and emissions per capita for each of these seven pollutants.

Race to the Top or Race to the Bottom Hypotheses. What could be the overall effect of TTIP on the environment? To capture the possible effect of TTIP on pollution, we employ the trade intensity term (denoted by $T$, the sum of bilateral exports and imports between each EU member and the US over GDP) and report it in the first row of Tables 4 through 12. We find strong statistically significant evidence suggesting the existence of race to the top hypothesis owing to the implementation of TTIP for $\mathrm{CH}_{4}, \mathrm{HFCs} / \mathrm{PFCs} / \mathrm{SF}_{6}, \mathrm{~N}_{2} \mathrm{O}, \mathrm{NH}_{3}$, and $\mathrm{SF}_{6} .{ }^{11)}$ This is an important positive result of this study because it shows that the implementation

11) Although for $\mathrm{CH}_{4}$ it is statistically significant when using $\mathrm{M} 1$ under each econometric technique, M2 when employing fixed effects with cross-sectional dependent robust standard errors, and M3 when using the random effects. In the case of $\mathrm{HFCs} / \mathrm{PFCs} / \mathrm{SF}_{6}$, it is not statistically significant only under $\mathrm{M} 2$ when employing the serial correlation fixed effects with Driscoll-Kraay robust standard errors. For $\mathrm{N}_{2} \mathrm{O}$, it is not statistically significant when employing the serial correlation fixed effects with Driscoll-Kraay robust standard errors under each model and when using M3. In the case of $\mathrm{NH}_{3}$, it is not statistically significant only under M2 and M3 when employing the simple fixed effects and fixed effects with cross-sectional dependent robust standard errors and under each model when using the serial correlation fixed effects with Driscoll-Kraay robust standard errors. For $\mathrm{SF}_{6}$, it is strongly statistically significant only when employing M3 under all four empirical specifications employed in this study, except for the serial correlation fixed effects with Driscoll-Kraay robust standard errors. 
of TTIP may be beneficial to the environment, as it helps reduce per capita pollution emissions of $\mathrm{CH}_{4}, \mathrm{HFCs} / \mathrm{PFCs} / \mathrm{SF}_{6}, \mathrm{~N}_{2} \mathrm{O}, \mathrm{NH}_{3}$, and $\mathrm{SF}_{6}$. Taking a closer look at Tables 5, 6, 11, and 12, we observe that, in a typical TTIP member, the implementation of TTIP could reduce per capita emissions of $\mathrm{N}_{2} \mathrm{O}, \mathrm{CH}_{4}, \mathrm{NH}_{3}$, and $\mathrm{SF}_{6}$ because Pollution Haven Hypothesis One is dominated by factor endowment hypothesis and Pollution Haven Hypothesis Two. In simple terms, more openness to trade between the US and the EU could help reduce per capita emissions of these four air pollutants because they are labor-abundant and densely populated, and typical EU members appear to be more environmentally efficient despite being poorer than the US.

As shown in Table 4, the result for HFCs/ PFCs/ $\mathrm{SF}_{6}$ stands because of Pollution Haven Hypothesis Two (see the signs and statistical significance of the coefficients of $T(R L P C)_{i t}$ and $T(R L P C)_{i t}^{2}$ variables). In addition, note that Pollution Haven Hypothesis One and factor endowment hypothesis are absent in this case because their related coefficients are not statistically significant. In other words, the implementation of TTIP may help reduce per capita emissions of HFCs/ PFCs/ $\mathrm{SF}_{6}$ because the US is more sparsely populated than most EU members; therefore, the US would act as a pollution haven (remember that only Finland and Sweden are more sparsely populated than the US, all the other EU members are more densely populated than the US).

However, there are also potentially negative consequences regarding the effects of the implementation of TTIP on the environment. We find statistically significant evidence consistent with the race to the bottom hypothesis. In particular, we find that the implementation of TTIP may increase per capita emissions of $\mathrm{SO}_{2}$ (see Table 7, where the results for $\mathrm{SO}_{2}$ are strongly statistically significant, regardless of the model or the statistical specification used in this study) and municipal waste (see Table 8 , where the results for municipal waste are strongly statistically significant for almost all models and empirical methodology). For $\mathrm{SO}_{\mathrm{x}}$, the results are statistically significant, but their signs are sensitive to the empirical methodology and/or the model used in this study (i.e., they are positive and strongly statistically significant under M2 when employing each of our empirical methodology except for the random effects, and under M3 when using simple fixed effects and fixed effects with cross-sectional dependent robust standard errors. However, the coefficient of the trade intensity variable is negative and statistically significant under M1 when using fixed effects with cross-sectional dependent robust standard errors). In the case of $\mathrm{NO}_{\mathrm{x}}$, the results are generally not statistically significant, and the signs of the trade intensity coefficients are sensitive to the models and/or the empirical specification used in this study; however, they are positive and statistically significant only under M2 when employing the fixed effects with cross-sectional dependent robust standard errors and simple fixed effects, and under M3 when using the random effects. ${ }^{12}$ )

12) It could be worth noting here that, in the previous two versions of this paper, we employ the exact same dataset (1989-2013 and 29 TTIP members with the UK included in the dataset) as the one used in Qirjo and Pascalau (2019b). In these two earlier versions, we find that the implementation of TTIP could help decrease (increase) 
Further Globalization Effects. Bilateral trade between the US and a subset of EU members in the sample could be influenced by geographical, cultural, or political reasons. In particular, some TTIP members use English as an official language, have access to the sea or ocean, or adopt the same currency. To capture these effects, as described in Qirjo and Pascalau (2019b), we employ three dummy variables. In the first one, we use the cross-product of the trade intensity variable with a dummy that is 1 if the official language is English (English=1) and 0 otherwise. This is denoted by English $=1 \times$ Trade, and is reported in the sixteenth row.

In the second one, we employ the cross-product of trade with the Sea dummy, which is 1 if the TTIP member has access to the sea or the ocean $(\mathrm{Sea}=1)$ and 0 otherwise. This is denoted by $S e a=1 \times$ Trade, and is reported in the seventeenth row.

Finally, for the third dummy variable, we use the cross-product of the trade intensity variable with the Euro dummy, where an EU member gets a value of 1 for the years that have adopted Euro as their official language (Euro=1) and 0 otherwise. This is denoted by Euro $=1 \times$ Trade, and it is reported in the eighteenth row of Tables 4 through 12 .

We find statistically significant evidence, implying that the implementation of TTIP in countries that use English as an official language may increase per capita emissions of $\mathrm{N}_{2} \mathrm{O}$, $\mathrm{HFCs} / \mathrm{PFCs} / \mathrm{SF}_{6}, \mathrm{CH}_{4}, \mathrm{SF}_{6}, \mathrm{SO}_{\mathrm{x}}, \mathrm{NO}_{\mathrm{x}}$, and $\mathrm{NH}_{3}$ relative to countries where English is not an official language. Recall that, for $\mathrm{CH}_{4}, \mathrm{HFCs} / \mathrm{PFCs} / \mathrm{SF}_{6}, \mathrm{~N}_{2} \mathrm{O}, \mathrm{NH}_{3}$, and $\mathrm{SF}_{6}$, we find a negative relationship between trade intensity and their per capita emissions. Thus, the latter result combined with the result of this dummy variable implies that per capita emissions of each of the latter five air pollutants would be reduced less in TTIP members who use English as their official language (the US, Malta, and Ireland) than in the EU members that do not use English as their official language due to the implementation of TTIP. This could be because, on average, per capita emissions of the latter five air pollutants may be reduced more in the ex-communist members of the EU, which could produce more labor-intensive goods owing to higher trade intensity with the US.

The results show that the implementation of TTIP in countries with sea or ocean access may reduce per capita emissions of $\mathrm{CH}_{4}, \mathrm{NH}_{3}, \mathrm{HFCs} / \mathrm{PFCs} / \mathrm{SF}_{6}$, and $\mathrm{N}_{2} \mathrm{O}$ relative to landlocked countries. This could suggest that, for the latter four air pollutants, their emissions per capita, as a consequence of TTIP, could be reduced more in countries that have sea access because they trade more with the US than landlocked EU members due to shipping cost differences.

We report statistically significant evidence indicating that the implementation of TTIP in Eurozone members may see more per capita emissions of $\mathrm{SO}_{2}$, municipal waste, and $\mathrm{SO}_{\mathrm{x}}$ than non-Eurozone members. Remember, as shown above, the implementation of TTIP may help increase per capita emissions of $\mathrm{SO}_{2}$ and municipal waste, respectively. Hence, in the case of 
the latter two pollutants, these two results may imply that, because of the implementation of TTIP, per capita emissions of $\mathrm{SO}_{2}$ and municipal waste could be increased more in Eurozone members because they trade more as a group with the US owing to the lower exchange transaction costs compared with the non-Eurozone members. We show robust evidence implying that the implementation of TTIP in Eurozone members may help reduce more per capita emissions of $\mathrm{SF}_{6}, \mathrm{NH}_{3}$, and $\mathrm{N}_{2} \mathrm{O}$ compared with the non-Eurozone members. Using an analogous analysis with $\mathrm{SO}_{2}$ above (see the results for the trade intensity variable for $\mathrm{SF}_{6}, \mathrm{NH}_{3}$, and $\mathrm{N}_{2} \mathrm{O}$ ), it could be that more trade between the former EU members and the US is associated with lower per capita emissions of $\mathrm{SF}_{6}, \mathrm{NH}_{3}$, and $\mathrm{N}_{2} \mathrm{O}$, respectively.

In Tables 13-30, similar to Qirjo and Pascalau (2019b), we use two different instrumental approaches for robustness purposes. In particular, in Tables 13 through 21, we provide evidence of the robustness of our results for our pollutants by employing the lag of trade as an instrumental variable for the contemporaneous variable of trade. Similarly, in Tables 22 through 30, we provide another robustness check for our pollutants using an instrumental approach based on the gravity model, similar to Frankel and Rose (2005). For more details on each of these two instrumental variable approaches, see Pascalau and Qirjo (2017a). The results of Tables 13-21 and 22-30, generally resemble those of Tables 4-12, respectively.

\section{Conclusion}

This study evaluated the effect of the possible implementation of a TTIP on nine pollutants: $\mathrm{SO}_{2}, \mathrm{SO}_{\mathrm{x}}, \mathrm{CH}_{4}, \mathrm{HFCs} / \mathrm{PFCs} / \mathrm{SF}_{6}, \mathrm{~N}_{2} \mathrm{O}, \mathrm{NO}_{\mathrm{x}}, \mathrm{SF}_{6}, \mathrm{NH}_{3}$, and municipal waste. We employ the same econometric techniques, models, and explanatory variables as in Qirjo and Pascalau (2019b). We use a panel dataset for 27 EU members and the US over the 1990-2018 time period.

We found that trade liberalization between the US and the EU could assist in the fight against global warming because it may reduce per capita emissions of six air pollutants in a typical TTIP member. In particular, we show that, on average, a $1 \%$ increase in bilateral trade between the US and a typical EU member may reduce yearly per capita emissions of $\mathrm{CH}_{4}$, HFCs/ PFCs/ $\mathrm{SF}_{6}, \mathrm{~N}_{2} \mathrm{O}, \mathrm{NH}_{3}$, and $\mathrm{SF}_{6}$ by about 4, 5, and $4 \mathrm{~kg}$ in $\mathrm{CO}_{2}$ in-equivalent, $26 \mathrm{Mt}$, and $574 \mathrm{~T}$ in $\mathrm{CO}_{2}$ in-equivalent, respectively. However, we also provide statistically significant evidence implying that lower trade barriers between the US and the EU could also denigrate the environment in these regions. That is, we report statistically significant evidence suggesting that a $1 \%$ increase in bilateral trade between the US and a typical EU member may increase yearly per capita emissions of $\mathrm{SO}_{2}$ and municipal waste by about 810 and $2360 \mathrm{~kg}$, respectively.

Focusing on the average TTIP member, we provide statistically significant evidence consistent with Pollution Haven Hypothesis One owing to the implementation of TTIP for $\mathrm{CH}_{4}, \mathrm{~N}_{2} \mathrm{O}$, 
$\mathrm{SF}_{6}, \mathrm{SO}_{2}, \mathrm{SO}_{\mathrm{x}}$, and $\mathrm{NH}_{3}$. Therefore, following Pollution Haven Hypothesis One, a typical EU member (poorer than the US) could act as a pollution haven for these six air pollutants owing to the implementation of TTIP. Furthermore, we found statistically significant evidence consistent with Pollution Haven Hypothesis Two from the implementation of TTIP for HFCs/ PFCs/ $\mathrm{SF}_{6}, \mathrm{~N}_{2} \mathrm{O}, \mathrm{CH}_{4}, \mathrm{SF}_{6}, \mathrm{SO}_{2}$, municipal waste, and $\mathrm{NH}_{3}$. In other words, the US may act as a pollution haven according to Pollution Haven Hypothesis Two for the latter seven pollutants. Moreover, we report statistically significant evidence consistent with factor endowment hypothesis due to the implementation of TTIP for $\mathrm{CH}_{4}, \mathrm{~N}_{2} \mathrm{O}, \mathrm{NH}_{3}$, and $\mathrm{SF}_{6}$. Thus, for these four air pollutants, the implementation of TTIP may reduce air pollution in labor-abundant EU members and increase it in capital-abundant ones.

As a typical EU member is a poorer, more labor-abundant, and more densely populated country compared with the US, we cannot theoretically predict the effects of the implementation of TTIP on the environment in an unambiguous way. We provide statistically significant evidence suggesting that, in the cases of $\mathrm{CH}_{4}, \mathrm{~N}_{2} \mathrm{O}, \mathrm{NH}_{3}$, and $\mathrm{SF}_{6}$, trade openness between the US and the EU could be beneficial to the environment because factor endowment hypothesis and Pollution Haven Hypothesis Two dominate Pollution Haven Hypothesis One. The implementation of TTIP may decrease the per capita emissions of HFCs/ PFCs/ $\mathrm{SF}_{6}$ because of the presence of Pollution Haven Hypothesis Two (Note that factor endowment hypothesis and Pollution Haven Hypothesis Two are not statistically significant in this case).

Our empirical findings are consistent with the results of game theoretical models that analyze the role of strategic trade policies on the environment. These theoretical models suggest that trade liberalization follows either the race to the bottom hypothesis (i.e., Copeland \& Taylor, 1995 ) or race to the top hypothesis (i.e., Bommer \& Schulze, 1999; Burguet \& Sempere, 2003; Lai \& $\mathrm{Hu}, 2008)$. It is also consistent with strategic theoretical frameworks that find that lower trade barriers have an ambiguous effect on pollution (i.e., Benarroch \& Weder, 2006; Bhattacharya \& Pal, 2010; Nkuiya, 2013). Our empirical results suggest that the possible implementation of TTIP may increase the per capita emissions of $\mathrm{SO}_{2}$ and municipal waste. Therefore, from a policy perspective [and also following the theoretical findings of (Copeland \& Taylor, 1995), who suggest that exporters of pollution-intensive goods prefer to secure a free-trade agreement before negotiating an IEA], we suggest that officials on both sides of the Atlantic carefully analyze the potential harmful effects of the implementation of TTIP on the latter two pollutants. It could be better to include an IEA (in the chapter entitled "Raw Materials and Energy" of the potential TTIP) that sets a target emission level or a percentage cut in emission policy rather than an IEA that sets a constant cut in emission policy (see Açıkgöz \& Benchekroun, 2017). Further, it could be more efficient from an environmental perspective to sign an IEA before signing a trade deal (see Benchekroun \& Yildiz, 2011).

We find statistically significant evidence implying that the implementation of TTIP in countries 
that have access to shipping ports may help reduce per capita emissions of $\mathrm{CH}_{4}, \mathrm{NH}_{3}, \mathrm{HFCs} /$ $\mathrm{PFCs} / \mathrm{SF}_{6}$, and $\mathrm{N}_{2} \mathrm{O}$ more than in landlocked countries. Moreover, we report statistically significant evidence, indicating that the implementation of TTIP in Eurozone members may reduce per capita emissions of $\mathrm{SF}_{6}, \mathrm{NH}_{3}$, and $\mathrm{N}_{2} \mathrm{O}$ more than in non-Eurozone members. However, the opposite is true for $\mathrm{SO}_{2}$, municipal waste, and $\mathrm{SO}_{\mathrm{x}}$. In addition, we provide statistically significant evidence, indicating that the implementation of TTIP in countries that use English as their official language may increase per capita emissions of $\mathrm{N}_{2} \mathrm{O}, \mathrm{HFCs} / \mathrm{PFCs} / \mathrm{SF}_{6}, \mathrm{CH}_{4}, \mathrm{SF}_{6}, \mathrm{SO}_{\mathrm{x}}$, $\mathrm{NO}_{\mathrm{x}}$, and $\mathrm{NH}_{3}$ compared with countries where English is not an official language.

\section{References}

Abrego, L., Perroni, C., Whalley, J., \& Wigle, R. M. (2001). Trade and environment: Bargaining outcomes from linked negotiations. Review of International Economics, 9(3), 414-428. doi: 10.1111/1467-9396.0 0289

Açıkgöz, ÖT., \& Benchekroun, H. (2017). Anticipated international environmental agreements. European Economic Review, 92, 306-336. doi: 10.1016/j.euroecorev.2016.11.011

Antweiler, W., Copeland, B. R., \& Taylor, M. S. (2001). Is free trade good for the environment? American Economic Review, 91(4), 877-908. doi: 10.1257/aer.91.4.877

Barrett, S. (1994). Strategic environmental policy and international trade. Journal of Public Economics, 54(3), 325-338. doi: 10.1016/0047-2727(94)90039-6

Benarroch, M., \& Weder, R. (2006). Intra-industry trade in intermediate products, pollution and internationally increasing returns. Journal of Environmental Economics and Management, 52(3), 675-689.doi: 10.1016 /j.jeem.2006.05.001

Benchekroun, H., \& Yildiz, H. M. (2011). Free trade, autarky and the sustainability of an international environmental agreement. B.E. Journal of Economic Analysis and Policy, 11(1), 1-23. doi: 10.2202/193 $5-1682.2394$

Bhattacharya, R. N., \& Pal, R. (2010). Environmental standards as strategic outcomes: A simple model. Resource and Energy Economics, 32(3), 408-420. doi: 10.1016/j.reseneeco.2009.11.001

Bommer, R., \& Schulze, G. G. (1999). Environmental improvement with trade liberalization. European Journal of Political Economy, 15(4), 639-661. doi: 10.1016/S0176-2680(99)00037-3

Brander, J. A., \& Spencer, B. J. (1985). Export subsidies and international market share rivalry. Journal of International Economics, 18(1-2), 83-100. doi: 10.1016/0022-1996(85)90006-6

Burguet, R., \& Sempere, J. (2003). Trade liberalization, environmental policy, and welfare. Journal of Environmental Economics and Management, 46(1), 25-37. doi: 10.1016/S0095-0696(02)00032-3

CAIT. (2019). CAIT climate data explorer. Washington, DC: World Resources Institute. http://cait.wri.org

Carbone, J. C., Helm, C., \& Rutherford, T. F. (2009). The case for international emission trade in the absence of cooperative climate policy. Journal of Environmental Economics and Management, 58(3), 266-280. doi: 10.1016/j.jeem.2009.01.001 
Central Intelligence Agency. (2021). CIA world Factbook. https://www.cia.gov.

Cherniwchan, J., Copeland, B. R., \& Taylor, M. S. (2017). Trade and the environment: New methods, measurements, and results. Anmual Review of Economics, 9(1), 59-85. doi: 10.1146/annurev-economics063016-103756

Cohen, M. A., \& Tubb, A. (2018). The impact of environmental regulation on firm and country competitiveness: A meta-analysis of the Porter hypothesis. Journal of the Association of Environmental and Resource Economists, 5(2), 371-399. doi: 10.1086/695613

Cole, M. A. (2003). Development, trade, and the environment: How robust is the environmental Kuznets curve? Environment and Development Economics, 8(4), 557-580. doi: 10.1017/S1355770X0300305

Cole, M. A., \& Elliott, R. J. R. (2003). Determining the trade-environment composition effect: The role of capital, labor and environmental regulations. Journal of Environmental Economics and Management, 46(3), 363-383. doi: 10.1016/S0095-0696(03)00021-4

Cole, M. A., \& Fredriksson, P. G. (2009). Institutionalized pollution havens. Ecological Economics, 68(4), 1239-1256. doi: 10.1016/j.ecolecon.2008.08.011

Cole, M. A., Rayner, A. J., \& Bates, J. M. (1997). The environmental Kuznets curve: An empirical analysis. Environment and Development Economics, 2(4), 401-416. doi: 10.1017/S1355770X97000211

Conrad, K. (1993). Taxes and subsidies for pollution-intensive industries as trade policy. Journal of Environmental Economics and Management, 25(2), 121-135. doi: 10.1006/jeem.1993.1037

Copeland, B. R. (1996). Pollution content tariffs, environmental rent shifting, and the control of cross-border pollution. Journal of International Economics, 40(3-4), 459-476. doi: 10.1016/0022-1996(95)01415-2

Copeland, B. R., \& Taylor, M. S. (1995). Trade and transboundary pollution. American Economic Review, 85(4), 716-737.

Copeland, B. R., \& Taylor, M. S. (2005). Trade and the environment: Theory and evidence. Princeton: Princeton University Press.

Davis, S. J., \& Caldeira, K. (2010). Consumption-based accounting of $\mathrm{CO}_{2}$ emissions. Proceedings of the National Academy of Sciences of the United States of America, 107(12), 5687-5692. doi: 10.1073/pn as.0906974107

European Environment Agency. (2019). European environment agency dataset. https://www.eea.europa.eu. Eurostat. (2020). Your key to European statistics database. https://ec.europa.eu/eurostat/data/database.

Finus, M., \& Al Khourdajie, A. (2018) Strategic environmental policy, international trade and self-enforcing Agreements: The role of consumers' taste for variety. Strategic Behavior and the Environment, 7(3-4), 317-350. doi: $10.1561 / 102.00000086$

Frankel, J. A. (2009). Environmental effects of international trade. HKS Faculty Research Working Paper Series, RWP 09-006, John F. Kennedy school of government. Cambridge, MA: Harvard University.

Frankel, J. A., \& Rose, A. K. (2005). Is trade good or bad for the environment? Sorting out the causality. Review of Economics and Statistics, 87(1), 85-91. doi: 10.1162/0034653053327577

Fujiwara, K. (2010). Strategic environmental policies and the gains from trade liberalization. Review of Development Economics, 14(2), 360-373. doi: 10.1111/j.1467-9361.2010.00558.x

Im, K. S., Pesaran, M. H., \& Shin, Y. (2003). Testing for unit roots in heterogeneous panels. Journal of Econometrics, 115(1), 53-74. doi: 10.1016/S0304-4076(03)00092-7 
Intergovernmental Panel on Climate Change. (2014). Intergovernmental panel on climate change. https://w ww.ipcc.ch/report/ar5/syr/

International Monetary Fund. (2021). International monetary fund database. https://www.imf.org

Kellenberg, D. K. (2009). An empirical investigation of the pollution haven effect with strategic environment and trade policy. Journal of International Economics, 78(2), 242-255.

Kreickemeier, U., \& Richter, P. M. (2014). Trade and the environment: The role of firm heterogeneity. Review of International Economics, 22(2), 209-225.

Lai, Y.-B., \& Hu, C.-H. (2008). Trade agreements, domestic environmental regulation, and transboundary pollution. Resource and Energy Economics, 30(2), 209-228.

Levinson, A. (2009). Technology, international trade, and pollution from US manufacturing. American Economic Review, 99(5), 2177-2192.

Levinson, A. (2010). Offshoring pollution: Is the United States increasingly importing polluting goods? Review of Environmental Economics and Policy, 4(1), 63-83.

Levinson, A., \& Taylor, M. S. (2008). Unmasking the pollution haven effect. International Economic Review, 49(1), 223-254.

LRTAP. (2020). The Convention on Long-Range Transboundary Air Pollution, UNECE-EMEP emissions Database, WebDab. https://www.ceip.at/webdab-emission-database/reported-emissiondata.

Markusen, J. R. (1975). International externalities and optimal tax structures. Journal of International Economics, 5(1), 15-29.

Markusen, J. R., Morey, E. R., \& Olewiler, N. (1995). Competition in regional environmental policies when plant locations are endogenous. Journal of Public Economics, 56(1), 55-77.

Mazzanti, M., \& Zoboli, R. (2009). Municipal waste Kuznets curves: Evidence on socio-economic drivers and policy effectiveness from the EU. Environmental and Resource Economics, 44(2), 203-230.

McAusland, C., \& Najjar, N. (2015, May). Carbon footprint taxes. Environmental and Resource Economics, 61(1), 37-70.

Melitz, M. J. (2003). The impact of trade on intra-industry reallocations and aggregate industry productivity. Econometrica, 71(6), 1695-1725.

NECNFR. (2020). National emission ceilings directive and national financial Regulation 14 classification sector database. https://www.eea.europa.eu/data-and-maps/data/national-emission-ceilings-nec-directiv e-inventory-17

Nkuiya, B. (2013). Trade structure, transboundary pollution and multilateral trade liberalization: The effects on environmental taxes and welfare. Environmental and Resource Economics, 55(3), 337-355.

Organization for Economic Co-Operation and Development. (2020). Organization for economic cooperation and development factbook. https://stats.oecd.org.

Pascalau, R., \& Qirjo, D. (2017a). The role of TTIP on the environment. MPRA Working Paper, No. 79652. Munich, Germany: University Library of Munich.

Pascalau, R., \& Qirjo, D. (2017b). TTIP and the environmental Kuznets curve. MPRA Working Paper, No. 80192. Munich, Germany: University Library of Munich.

Qirjo, D., \& Christopherson, R. (2016). Will TAFTA be good or bad for the environment? In V. Ramiah \& G. N. Gregoriou (Eds.), Handbook of environmental and sustainable finance (pp. 179-206). Cambridge, 
MA: Academic Press, Elsevier.

Qirjo, D., \& Pascalau, R. (2019a). The role of TTIP on other than $\mathrm{CO}_{2}$ air pollutants. MPRA Working Paper, No. 95633. Munich, Germany: University Library of Munich.

Qirjo, D., \& Pascalau, R. (2019b). The role of TTIP on the environment. Southern Economic Journal, 85(4), 1262-1285.

Qirjo, D., \& Pascalau, R. (2021). Would economic growth affect air pollution in light of the potential transatlantic trade and investment partnership? International Economics and Economic Policy, 18(1), 127-156.

Qirjo, D., Pascalau, R., \& Christopherson, R. (2020). TTIP and environmental consequences. SSRN Working Paper, No. 3583048.

Qirjo, D., Pascalau, R., \& Krichevskiy, D. (2019). CETA and air pollution. MPRA Working Paper, No. 95608. Munich, Germany: University Library of Munich.

Qirjo, D., Pascalau, R., \& Krichevskiy, D. (2020). The role of CETA on carbon dioxide, f-gases, methane, and nitrous oxide. MPRA Working Paper, No. 99646. Munich, Germany: University Library of Munich.

Qirjo, D., Pascalau, R., \& Krichevskiy, D. (2021). Comprehensive Economic and Trade Agreement (CETA) and air pollution. Journal of Environmental Economics and Policy, 10(3), 293-323.

Stern, D. I. (2006). Reversal of the trend in global anthropogenic sulfur emissions. Global Environmental Change, 16(2), 207-220.

Taylor, M. S. (2005). Unbundling the pollution haven hypothesis. Advances in Economic Analysis and Policy, 3(2), 1-28.

UNFCCC. (2019). United nations framework convention on climate change dataset. https://unfccc.int

United States Environmental Protection Agency. (2020). United states environmental protection agency. Retrieved from https://www.epa.gov

Whalley, J., \& Wigle, R. (1991). The international incidence of carbon taxes. In R. Dornbusch \& J. M. Poterba (Eds.), Global warming: Economic policy responses (pp. 233-263). Cambridge, MA: MIT Press.

Winchester, N., Paltsev, S., \& Reilly, J. M. (2011). Will border carbon adjustments work? B E Journal of Economic Analysis and Policy, 11(1), 1-27. 


\section{Descriptive Statistics}

Table 2. Summary Statistics and Unit Root Tests

\begin{tabular}{|c|c|c|c|c|c|c|c|}
\hline Variable & Dimension & $\mathrm{N}$ & Mean & SD & Min & Max & Unit Root Tests \\
\hline $\mathrm{SO}_{2}$ & Level & 812 & 25.00472 & 30.51932 & .412686 & 394.1046 & $-3.1676^{* * *}$ \\
\hline MW & Level & 812 & 458.5168 & 141.7561 & 99.68029 & 829.433 & $-5.4927 * * *$ \\
\hline $\mathrm{SO}_{\mathrm{x}}$ & Level & 812 & 447.7004 & 2473.592 & .4189981 & 20924.7 & $-3.5604 * * *$ \\
\hline $\mathrm{CH}_{4}$ & Level & 812 & 1.234833 & .6587492 & .4363462 & 4.459494 & -0.6408 \\
\hline $\mathrm{HFC} / \mathrm{PFC} / \mathrm{SF}_{6}$ & Level & 812 & .4278221 & 1.35295 & .0000291 & 0.900 & $-5.5041 * * * \dagger$ \\
\hline $\mathrm{N}_{2} \mathrm{O}$ & Level & 812 & .6853512 & .3808181 & .0882484 & 2.29286 & $-4.2634 * * *$ \\
\hline $\mathrm{NO}_{\mathrm{x}}$ & Level & 812 & 28.79832 & 17.33162 & 10.83718 & 121.7388 & $-7.0765^{* * *}$ \\
\hline $\mathrm{SF}_{6}$ & Level & 812 & 13.26152 & 25.20696 & .0027043 & 211.1113 & $-3.1995 * * * \dagger$ \\
\hline $\mathrm{NH}_{3}$ & Level & 812 & 9.72853 & 4.858191 & 2.564108 & 33.26424 & $-7.3048 * * *$ \\
\hline Trade & Level & 868 & .0354136 & .0345353 & .0016183 & .2702026 & $-4.6332 * * *$ \\
\hline I & Level & 784 & 30882.77 & 21911.27 & 1074.843 & 126536.2 & $-3.1270 * * * \dagger$ \\
\hline $\mathrm{K} / \mathrm{L}$ & Level & 756 & 325848.9 & 161791.3 & 25107.5 & 758243.9 & $-3.9701 * * *$ \\
\hline LPC & Level & 784 & .0150148 & .0142926 & .0006393 & .0672539 & 0.9922 \\
\hline RI & Level & 784 & .5777424 & .4026011 & .0242749 & 2.26679 & 0.9472 \\
\hline RKL & Level & 756 & .8132509 & .350961 & .0242749 & 0796994 & 1.913547 \\
\hline RLPC & Level & 784 & 1.287615 & 1.228385 & .0594204 & 5.80826 & 0.9856 \\
\hline $\mathrm{FDI} / \mathrm{K}$ & Level & 840 & .0287451 & .1182087 & -.0596125 & 1.882336 & $-7.9377 * * *$ \\
\hline
\end{tabular}

$* * *, * *$, and $*$ denote significance at the $1 \%, 5 \%$, and $10 \%$ significance level, respectively. For all series, with the exception of the "relative" series, we use the Z-t-tilde-bar statistic of the Im-Pesaran-Shin unit-root test where the AR parameter is panel specific. In all cases, we also include a time trend. For the "relative" series, we compute the Harris-Tzavalis unit-root test since the Im-Pesaran-Shin test did not meet the required assumptions. The null states that all panels contain unit roots, while the alternative states that some panels are stationary. + means that the variable is stationary around a mean and we use the natural log function.

Table 3. Relative (to the U.S.) Measures of Income, Capital/labor and Land per Capita Ratios

\begin{tabular}{cccc}
\hline Country & Relative Income & Relative K/L ratio & Relative LPC ratio \\
\hline Austria & 0.88275275 & $\mathbf{1 . 0 8 7 9 2 1 4 5}$ & 0.30168661 \\
Belgium & 0.82030001 & $\mathbf{1 . 2 3 1 3 5 9 7 5}$ & 0.08522707 \\
Bulgaria & 0.0893932 & 0.16494214 & 0.42386152 \\
Croatia & 0.20968183 & 0.52461046 & 0.38334224 \\
Cyprus & 0.35725012 & $\mathbf{1 . 1 1 6 1 2 2 3}$ & 0.2753035 \\
Czechia & 0.2764834 & 0.87519516 & 0.22486776 \\
Denmark & $\mathbf{1 . 0 7 7 1 2 4 4 9}$ & 0.91210905 & 0.23443621 \\
Estonia & 0.03275883 & 0.47283686 & 0.97243133 \\
Finland & 0.85781289 & $\mathbf{1 . 0 3 7 2 4 2 0 8}$ & $\mathbf{1 . 9 0 0 0 0 0 1 2}$ \\
France & 0.78238288 & $\mathbf{1 . 0 6 2 2 0 5 0 6}$ & 0.30315076 \\
Germany & 0.8362206 & 0.93594802 & 0.12920746 \\
Greece & 0.42431222 & $\mathbf{1 . 1 3 2 3 3 4 9 5}$ & 0.36113358 \\
\hline
\end{tabular}


Table 3. Continued

\begin{tabular}{cccc}
\hline Country & Relative Income & Relative K/L ratio & Relative LPC ratio \\
\hline Hungary & 0.20699083 & 0.47400064 & 0.27262786 \\
Ireland & 0.90920703 & $\mathbf{1 . 0 1 5 8 2 1 7 7}$ & 0.50476593 \\
Italy & 0.68699764 & $\mathbf{1 . 2 9 2 6 1 5 0 9}$ & 0.15288657 \\
Latvia & 0.16647907 & 0.62900777 & 0.85746696 \\
Lithuania & 0.16767927 & 0.38021064 & 0.59170949 \\
Luxembourg & $\mathbf{1 . 7 3 4 8 1 9 1 6}$ & $\mathbf{1 . 3 9 9 8 6 7 6 9}$ & 0.16307526 \\
Malta & 0.3655649 & 0.52381013 & 0.02311025 \\
Netherlands & 0.89830145 & 0.92412225 & 0.07589289 \\
Poland & 0.17713701 & 0.32041551 & 0.24193417 \\
Portugal & 0.39250351 & 0.91437265 & 0.26399789 \\
Romania & 0.39609195 & 0.25587954 & 0.33240099 \\
Slovakia & 0.23113826 & 0.57181149 & 0.26940837 \\
Slovenia & 0.37716753 & 0.81133769 & 0.29692341 \\
Spain & 0.53530541 & $\mathbf{1 . 0 2 7 0 7 1 3 4}$ & 0.34681152 \\
Sweden & $\mathbf{1 . 0 0 6 4 3 0 6 1}$ & $\mathbf{1 . 0 3 7 0 7 8 3 6}$ & $\mathbf{1 . 4 5 2 2 5 5 3 6}$ \\
U.S. & 1 & 1 & 1 \\
\hline
\end{tabular}




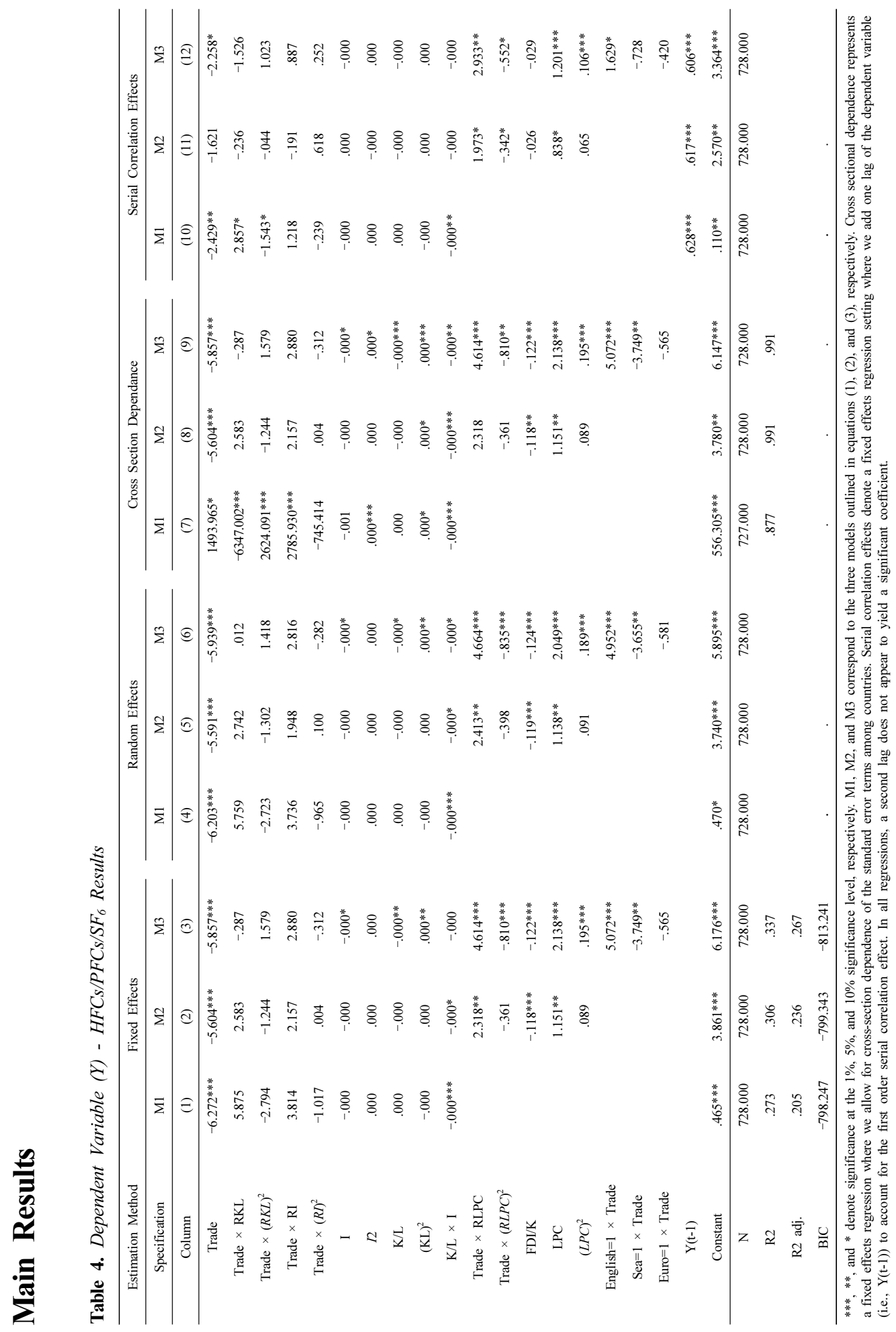




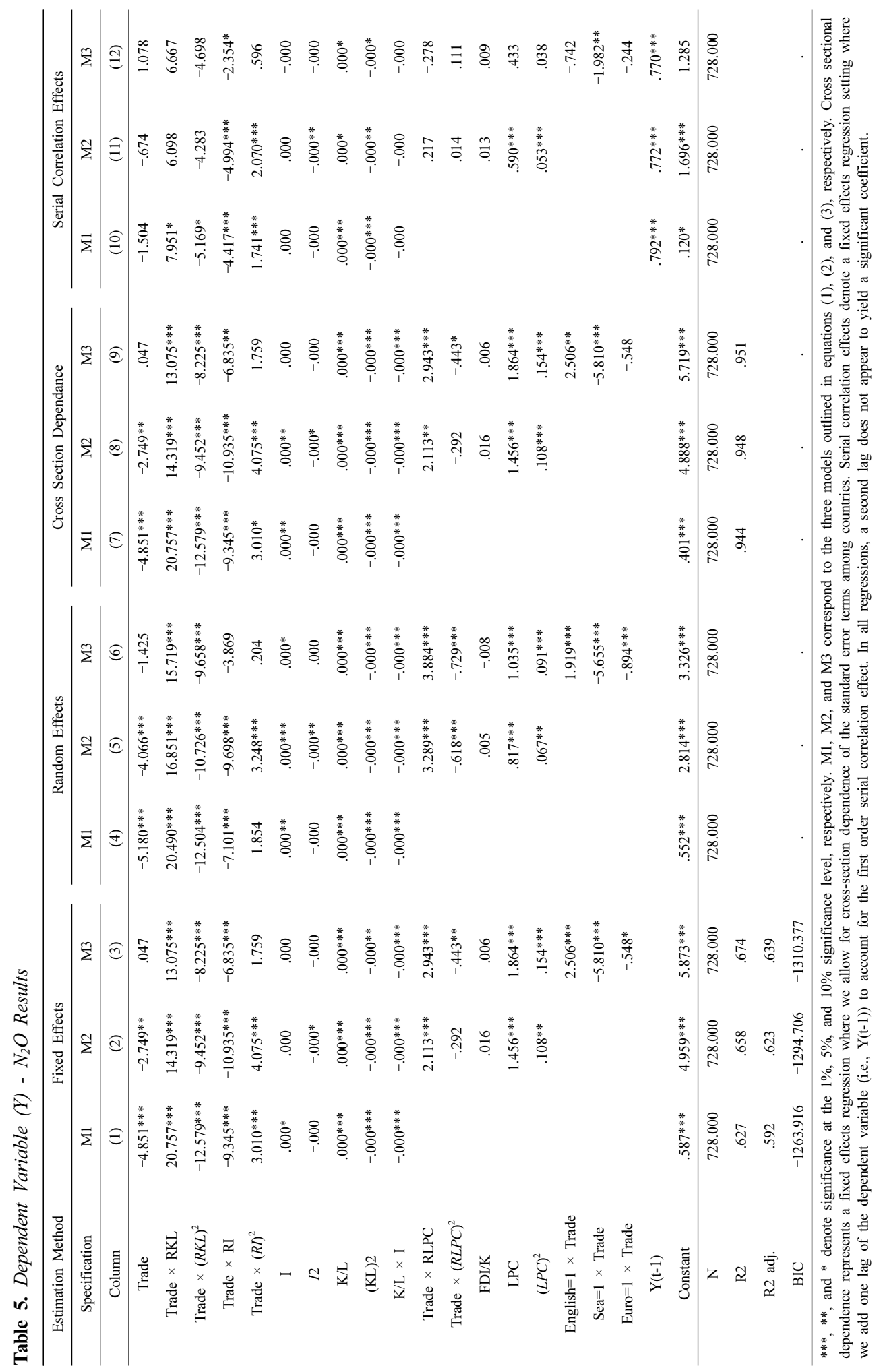




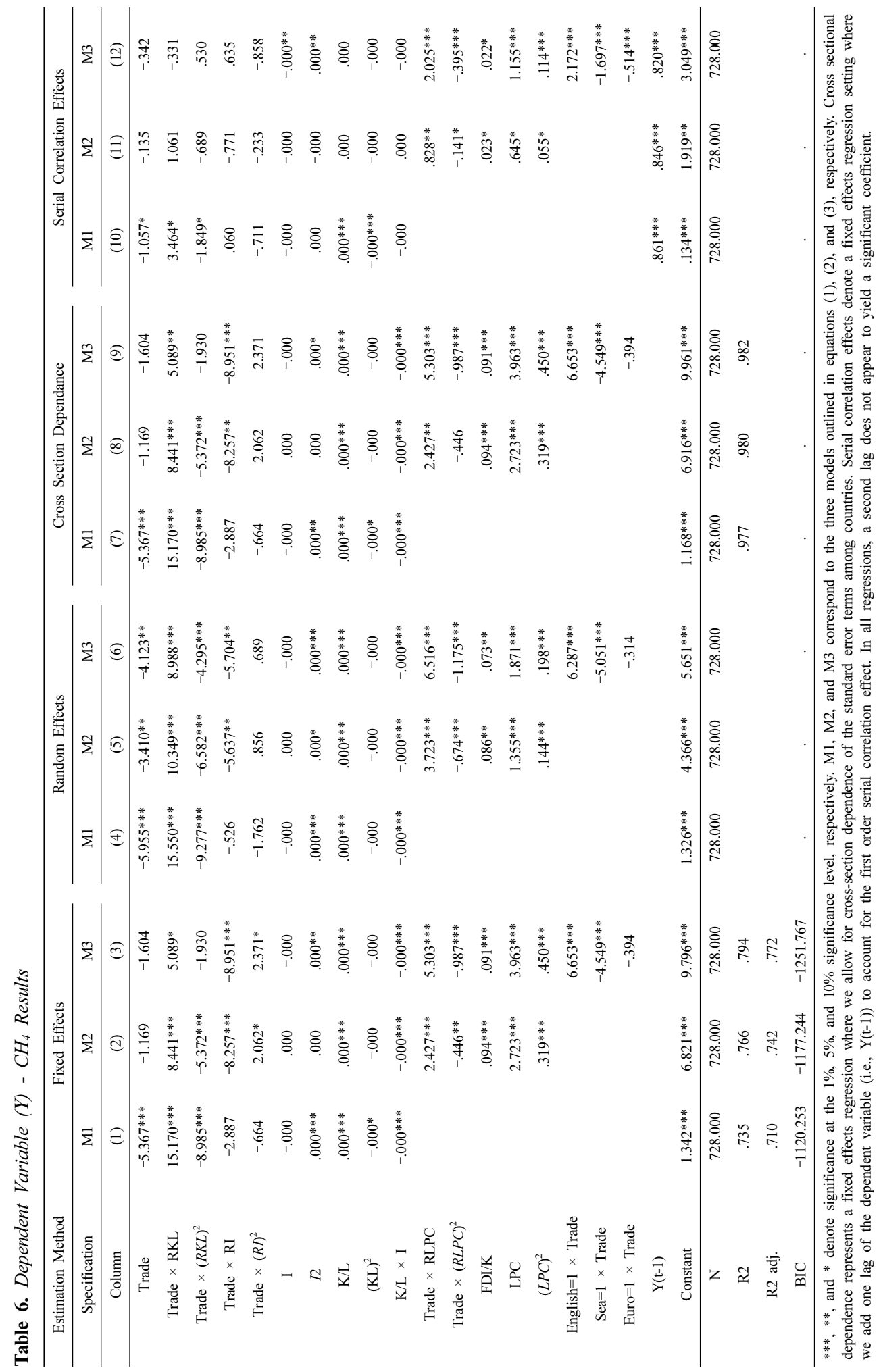




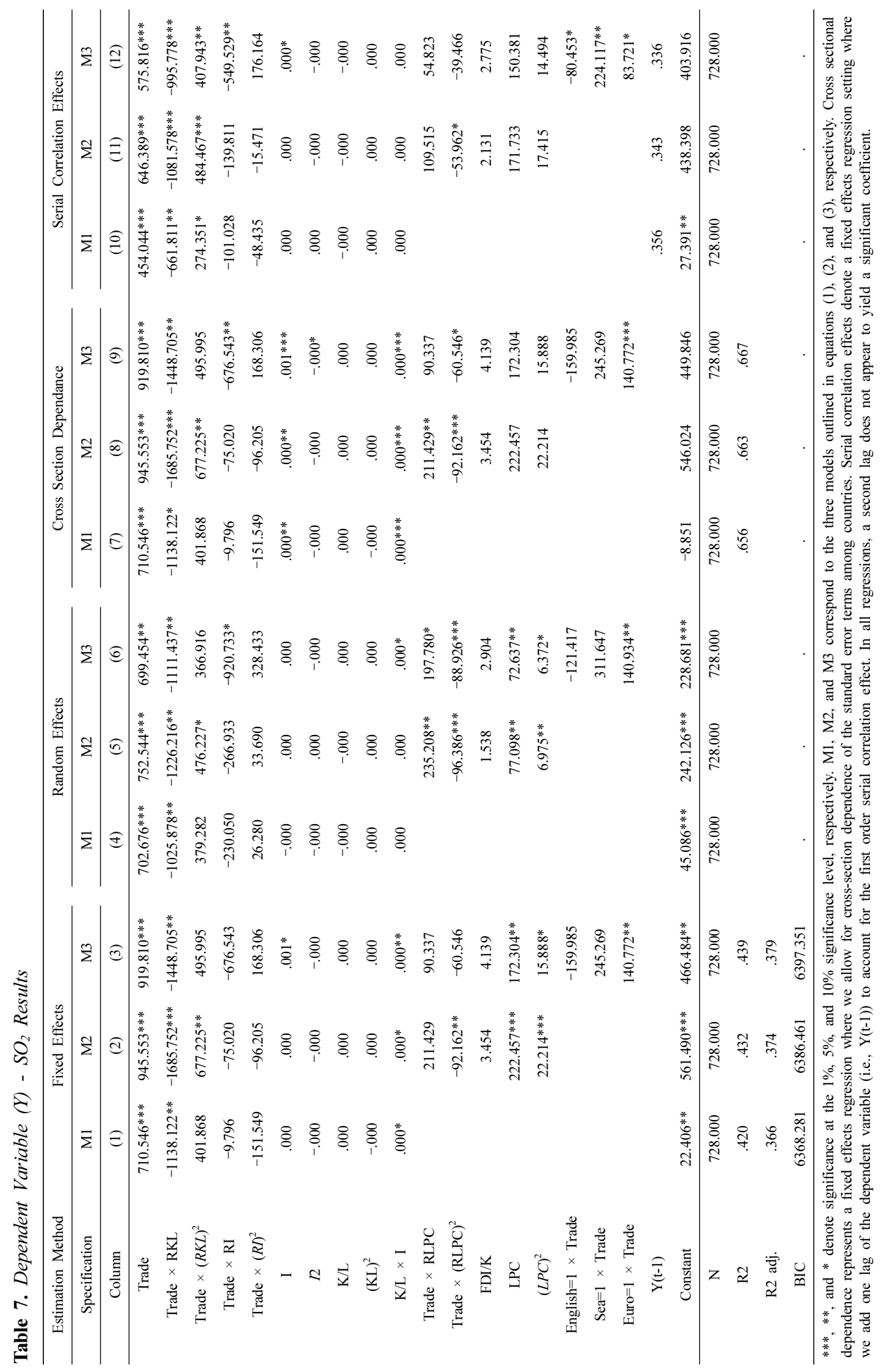




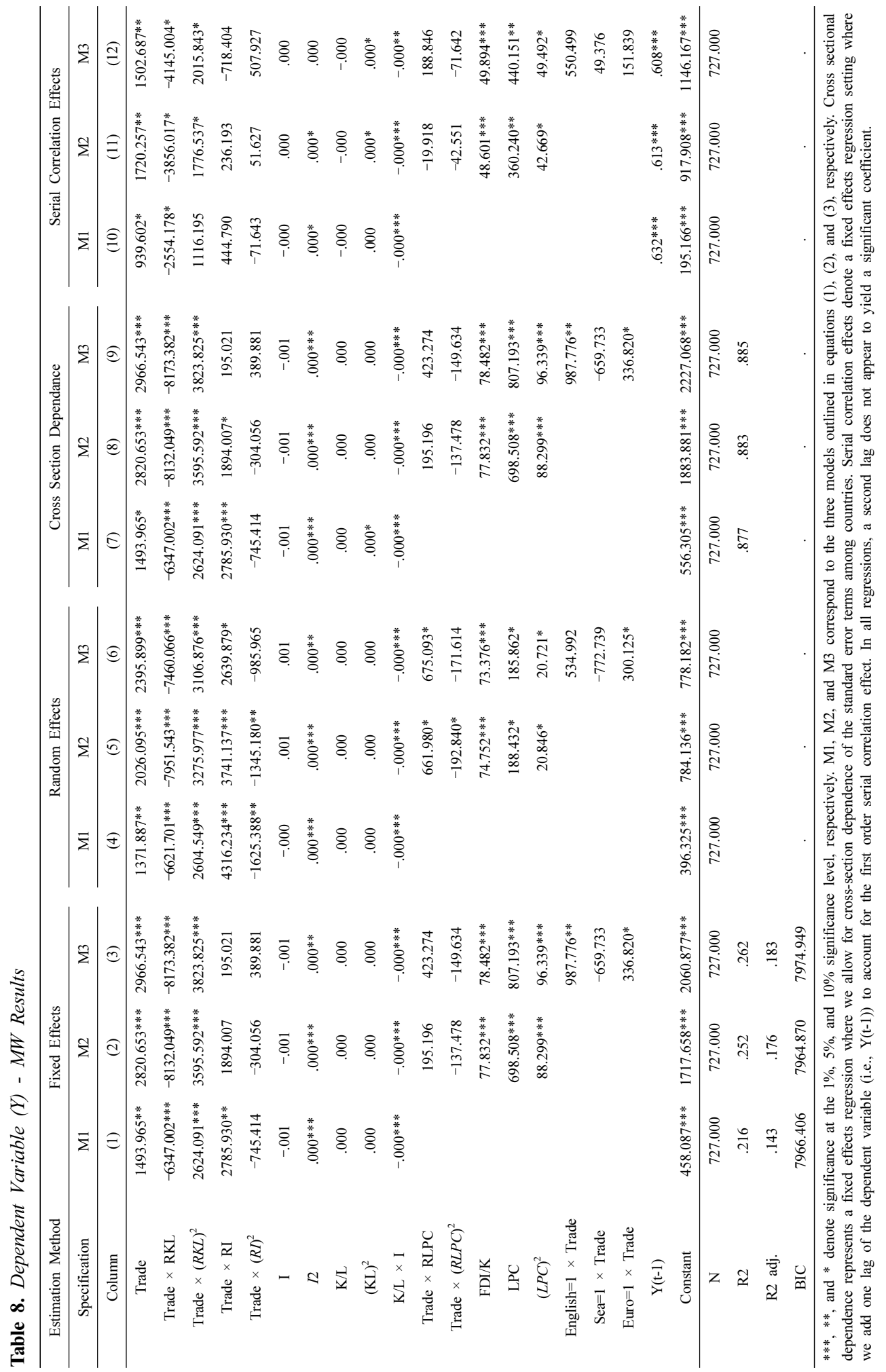




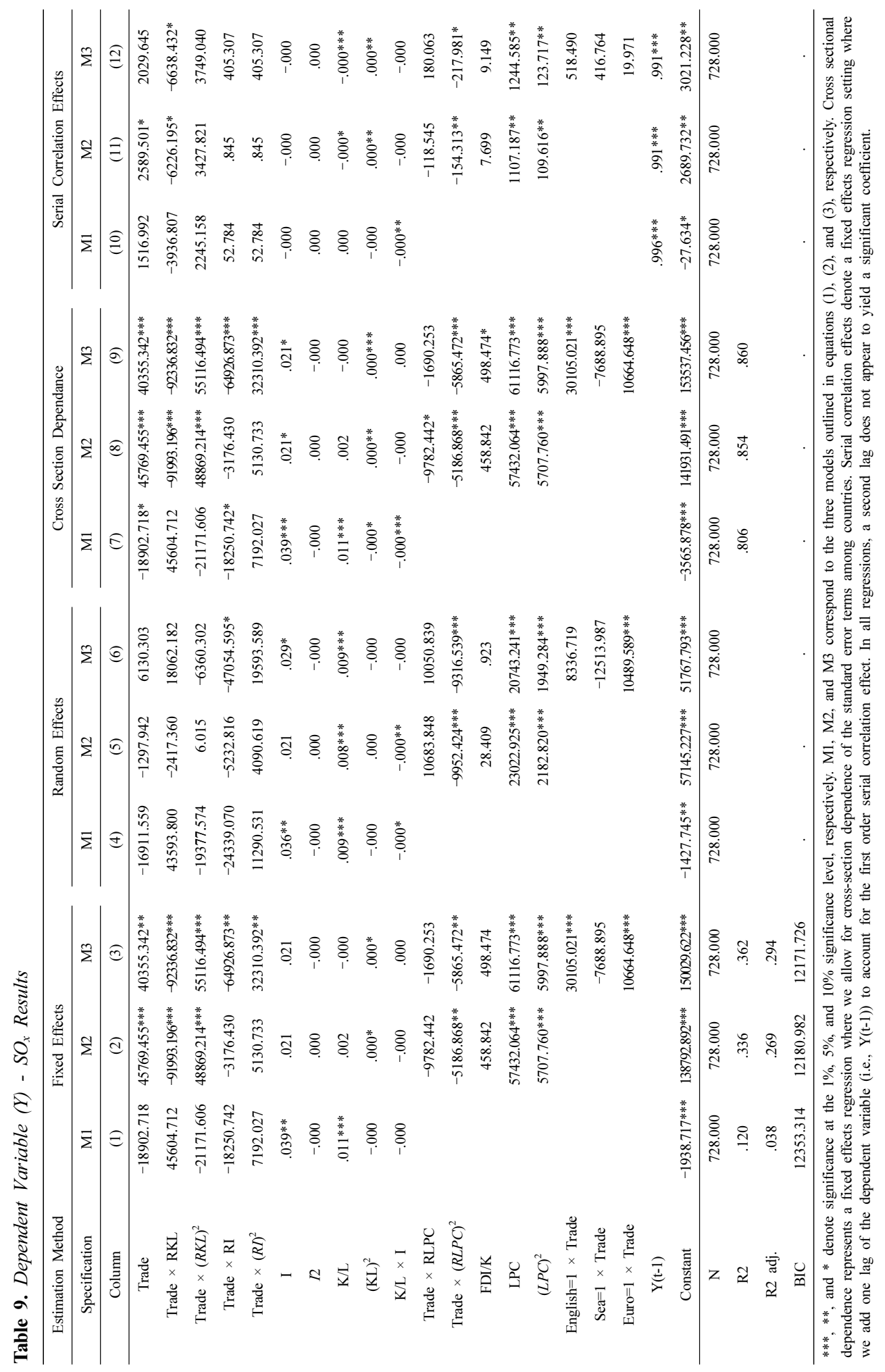




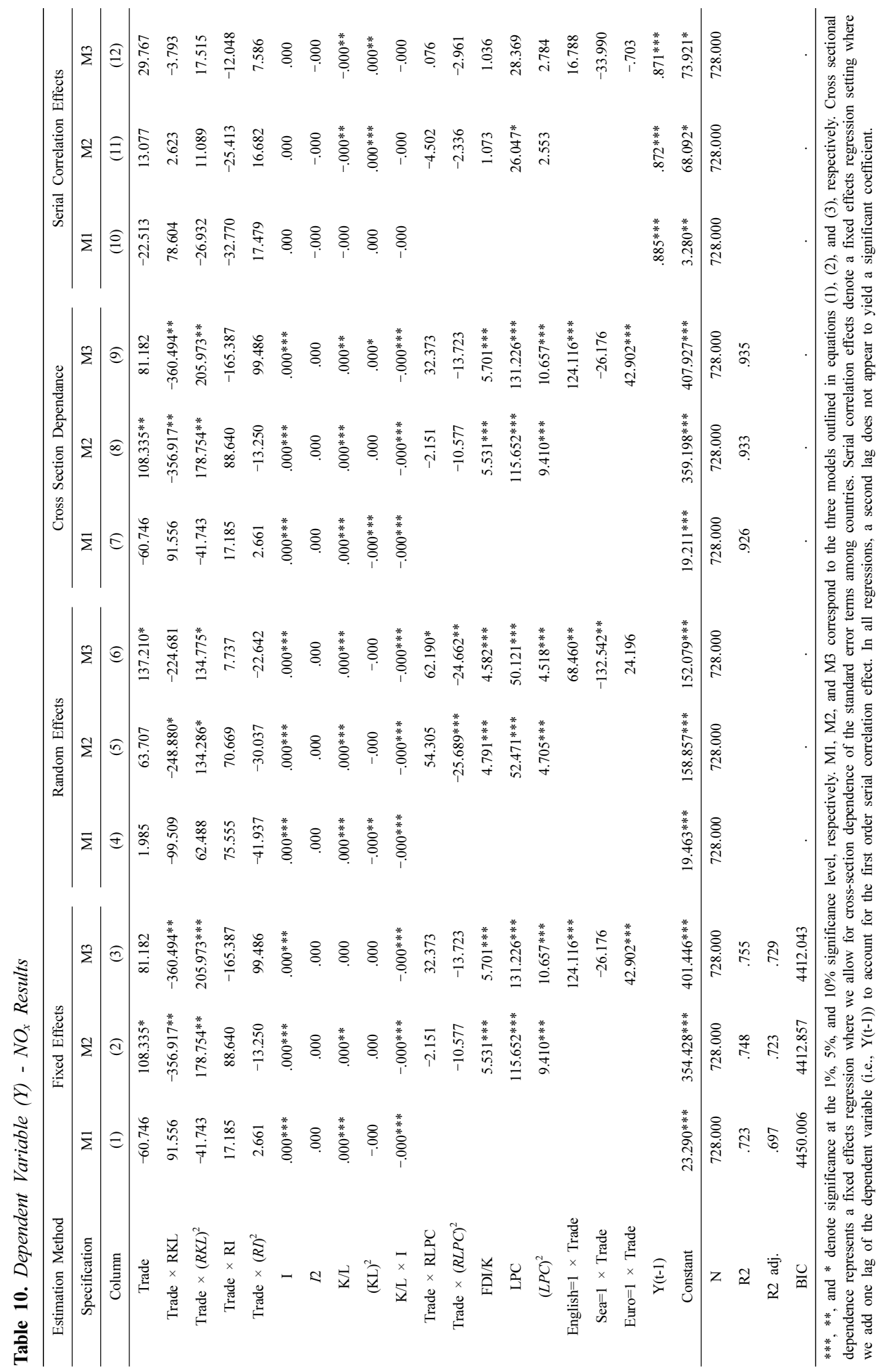




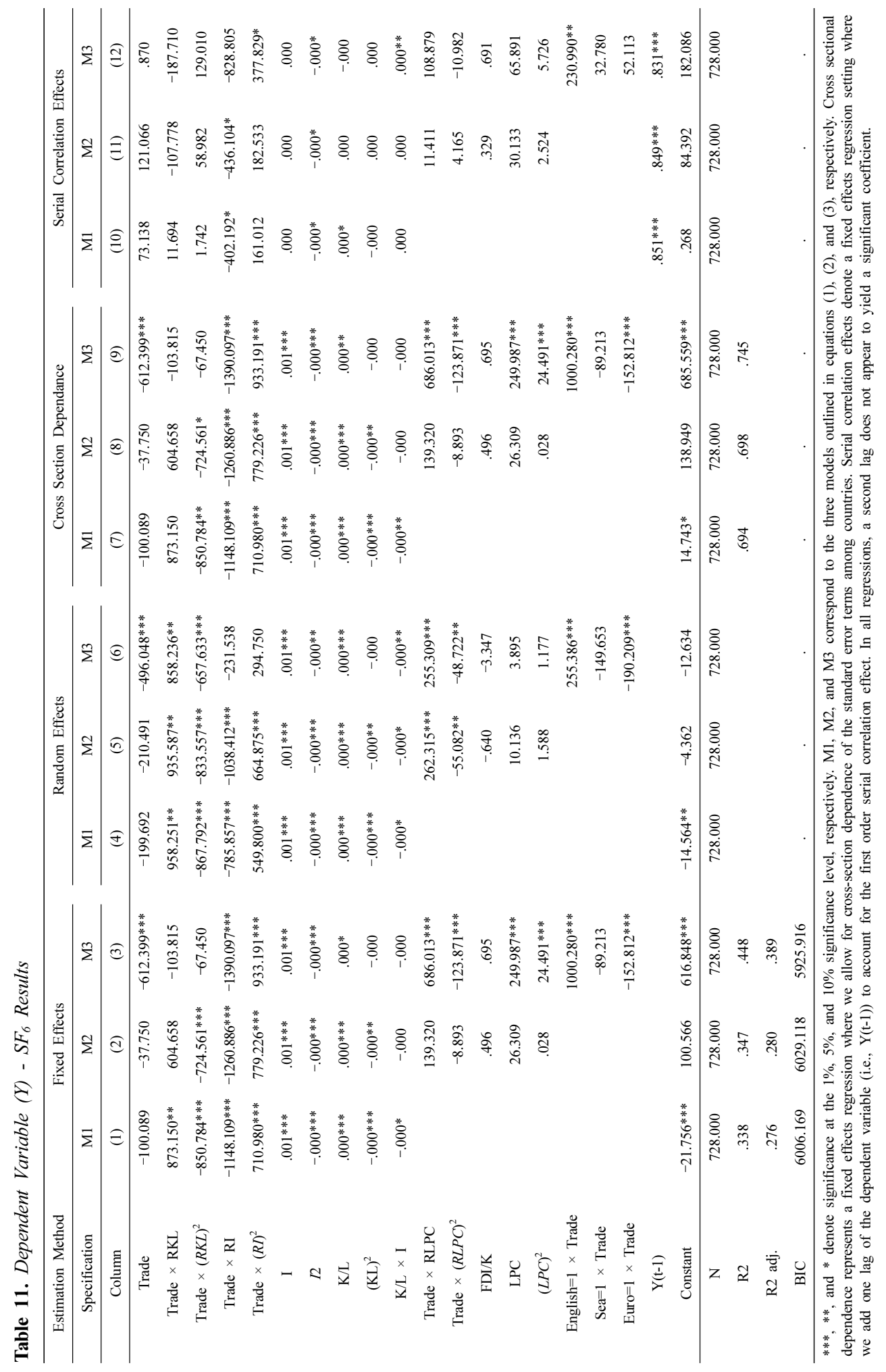




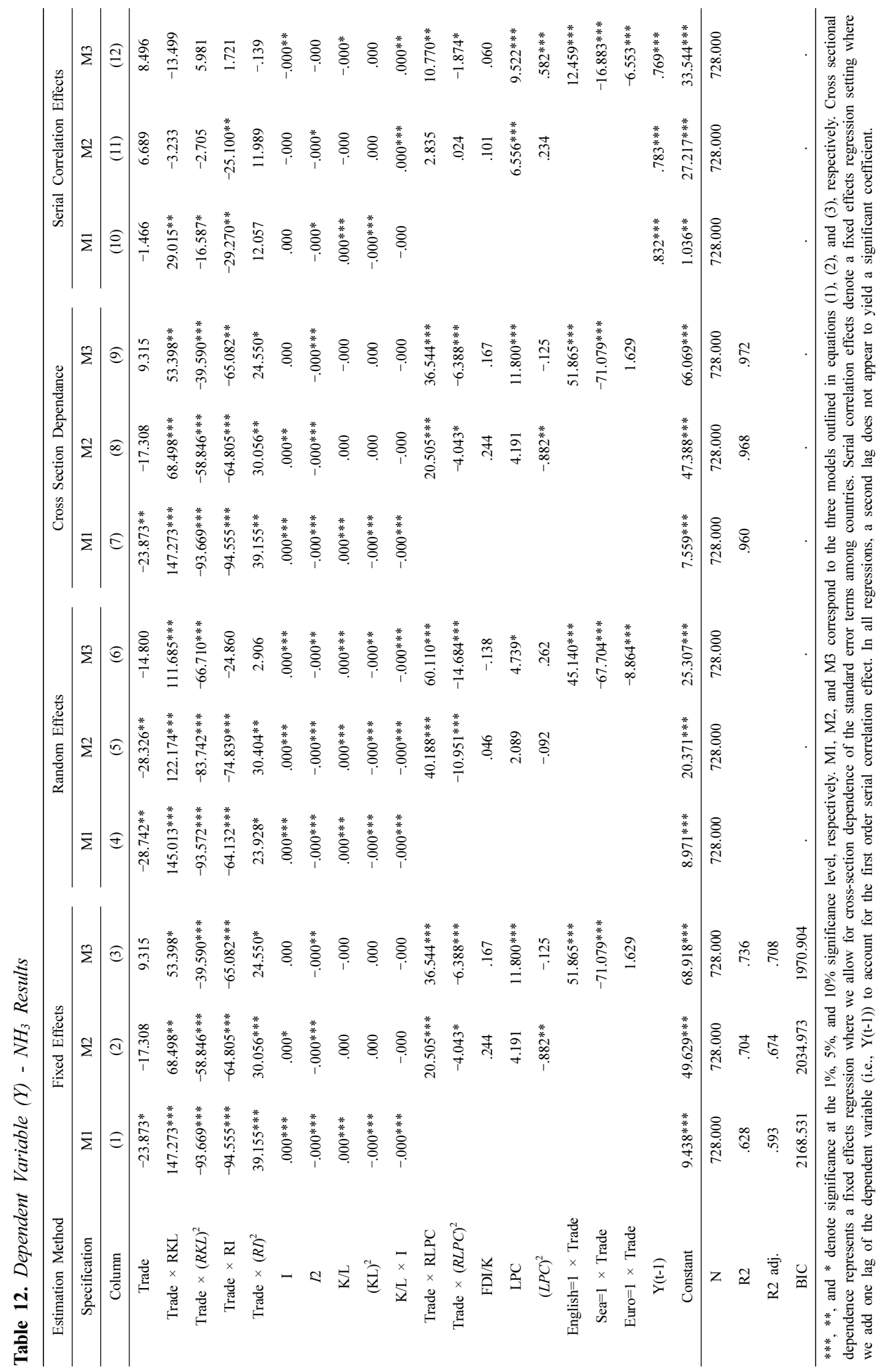




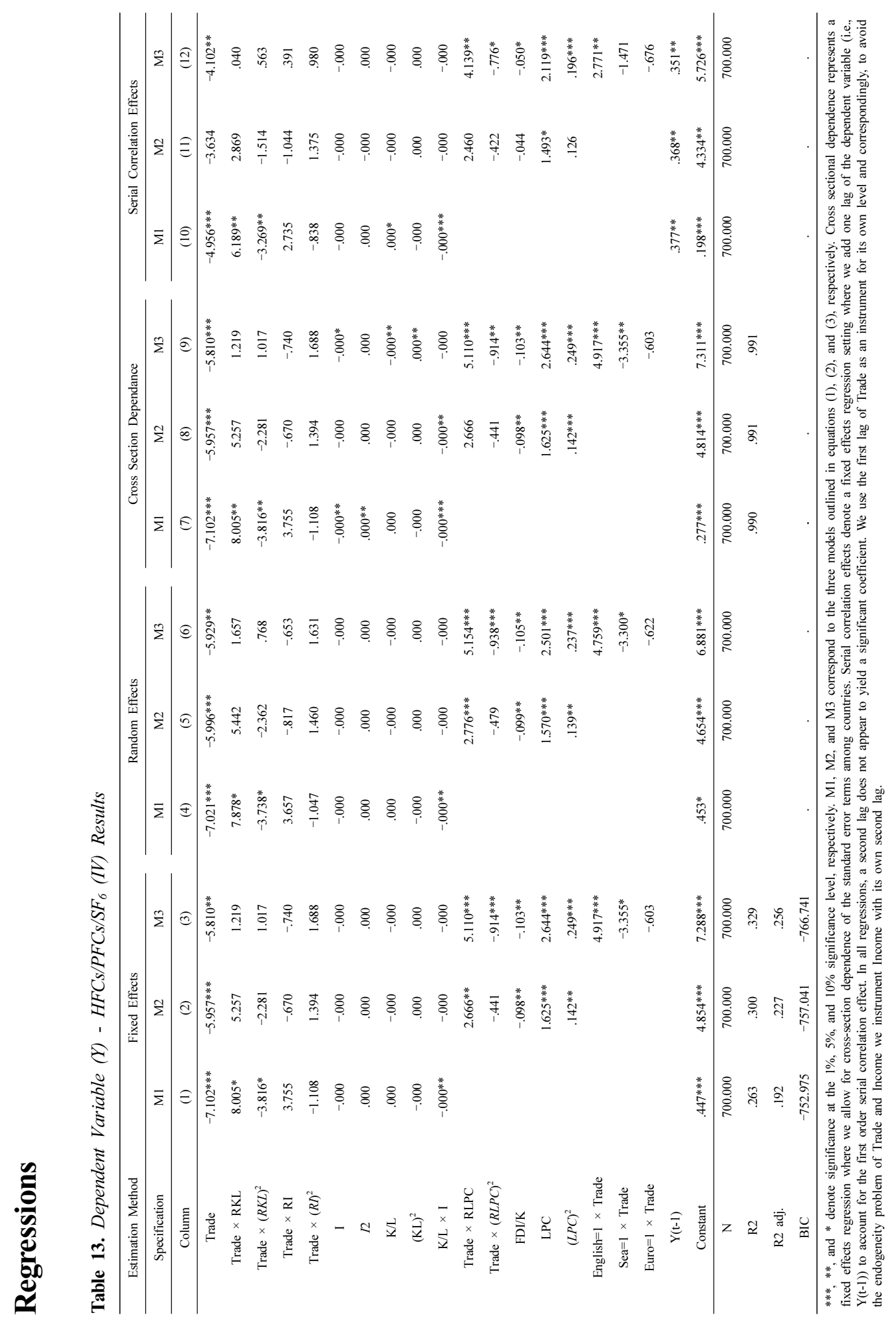




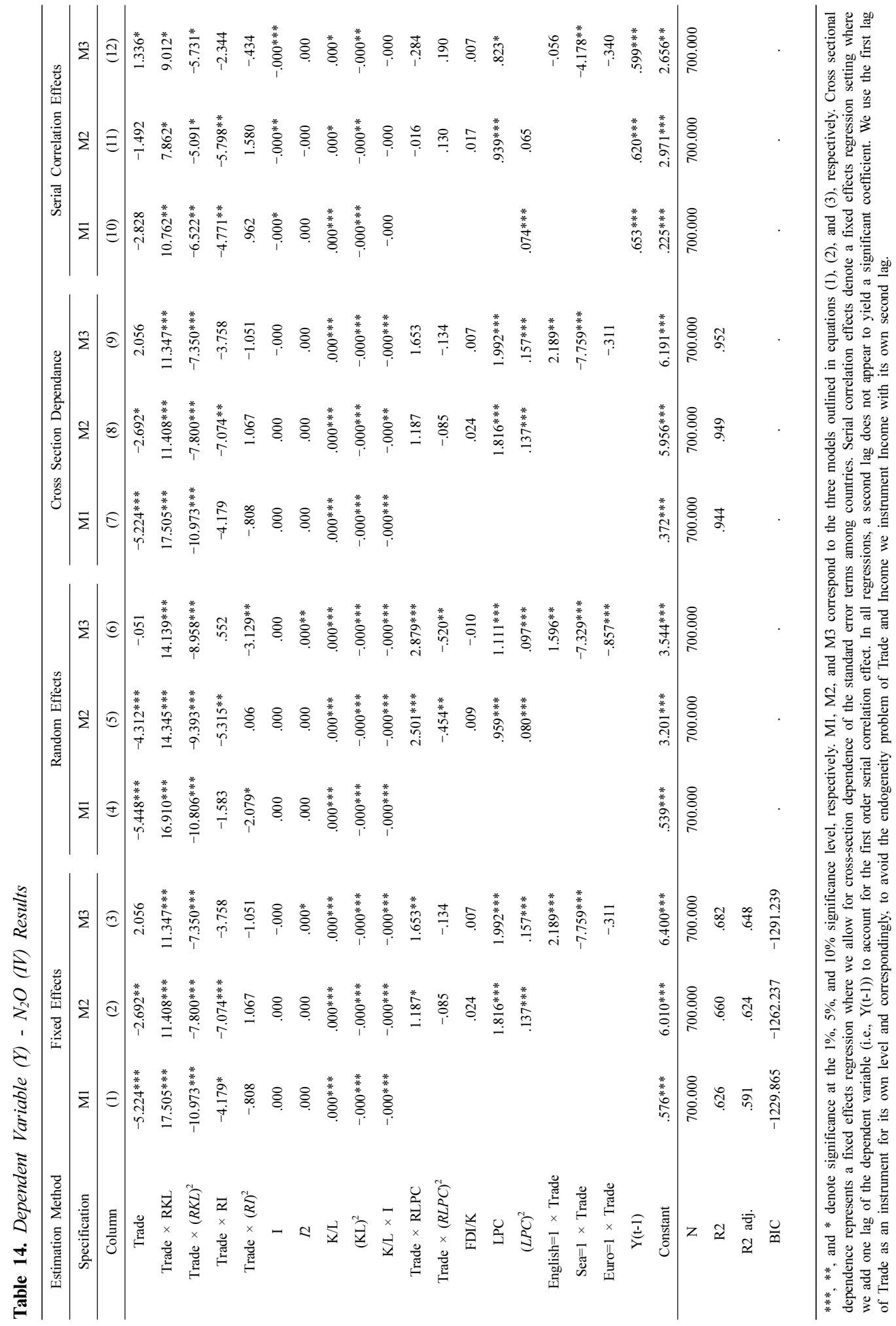




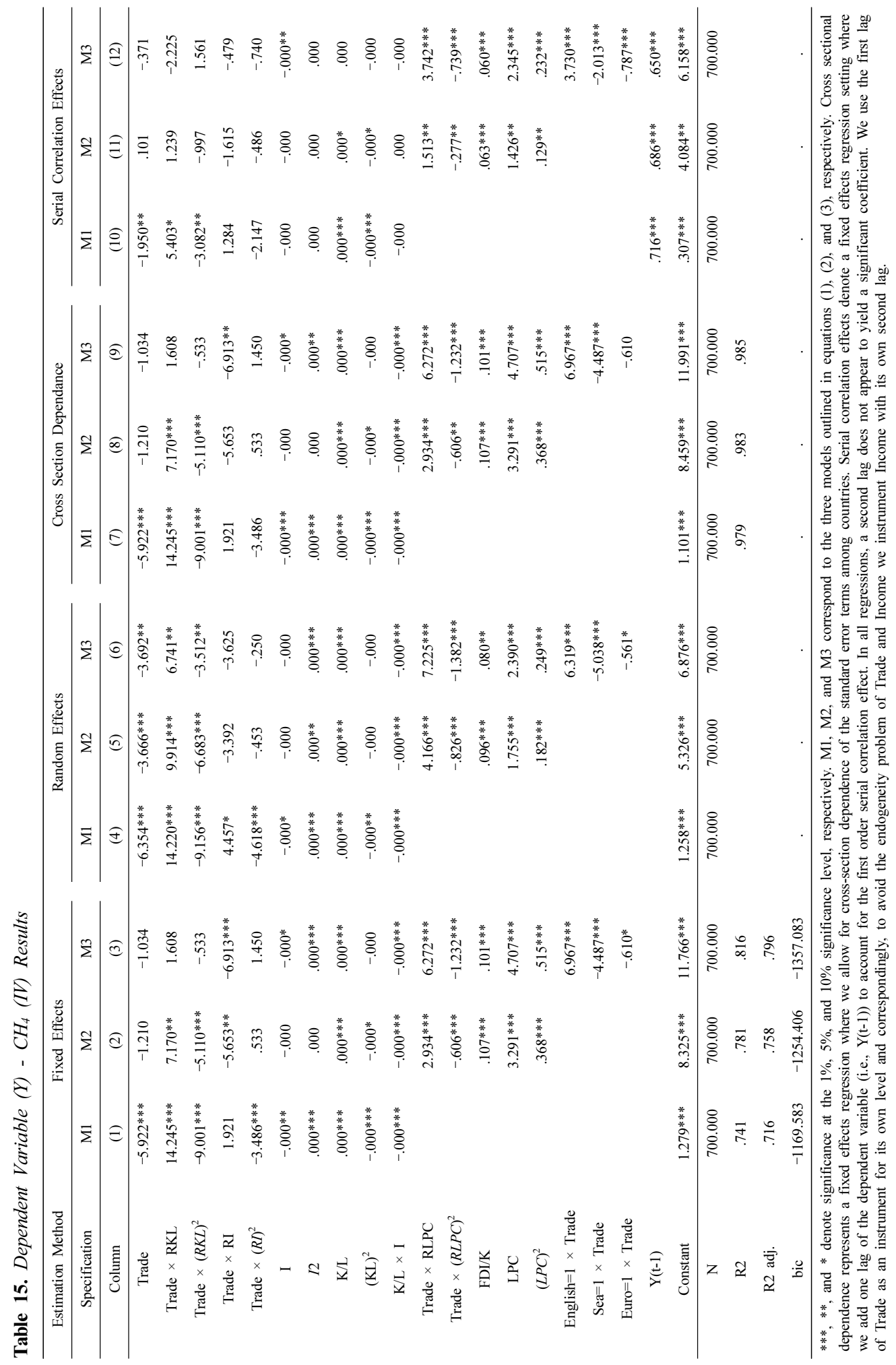




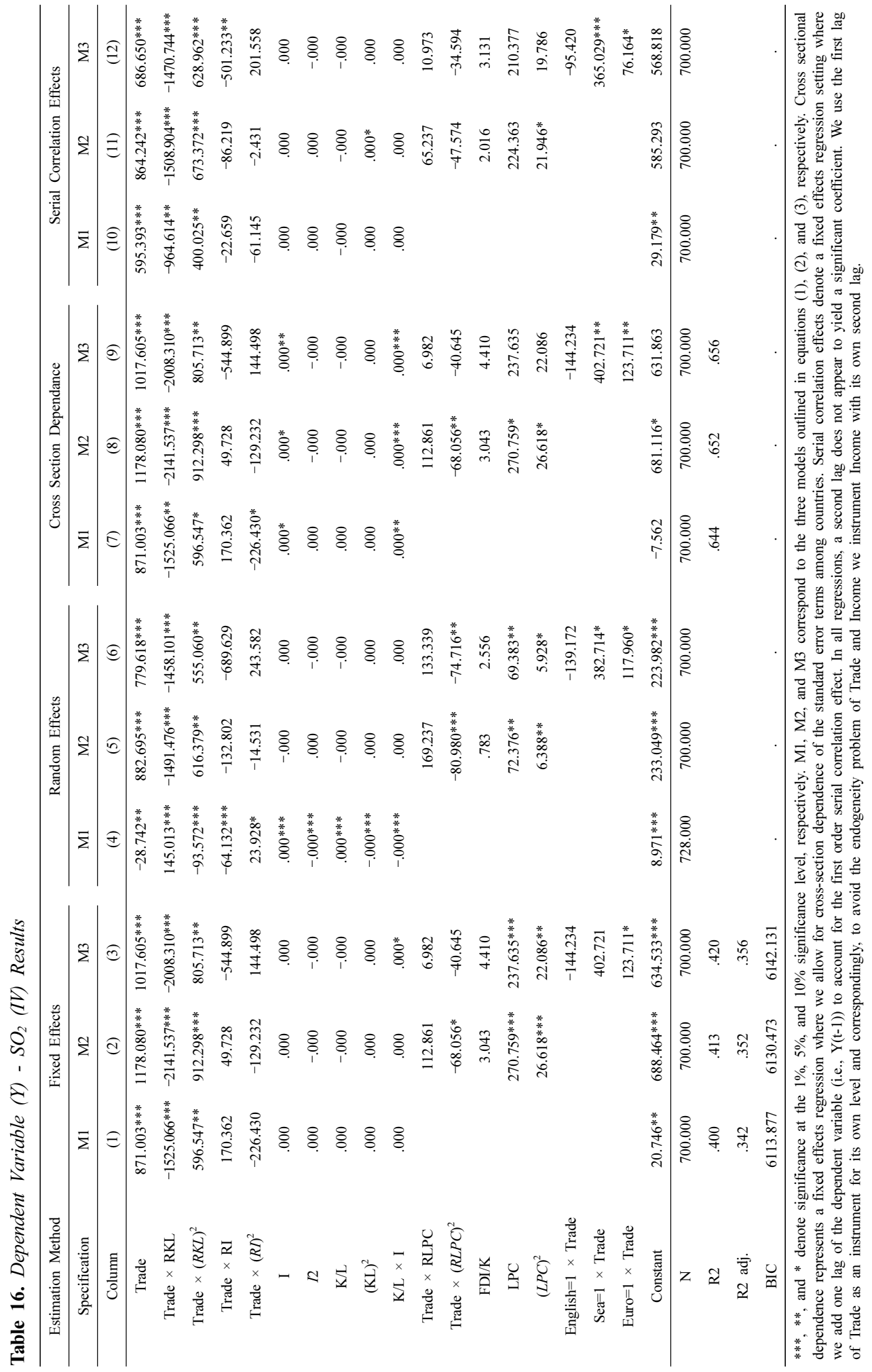




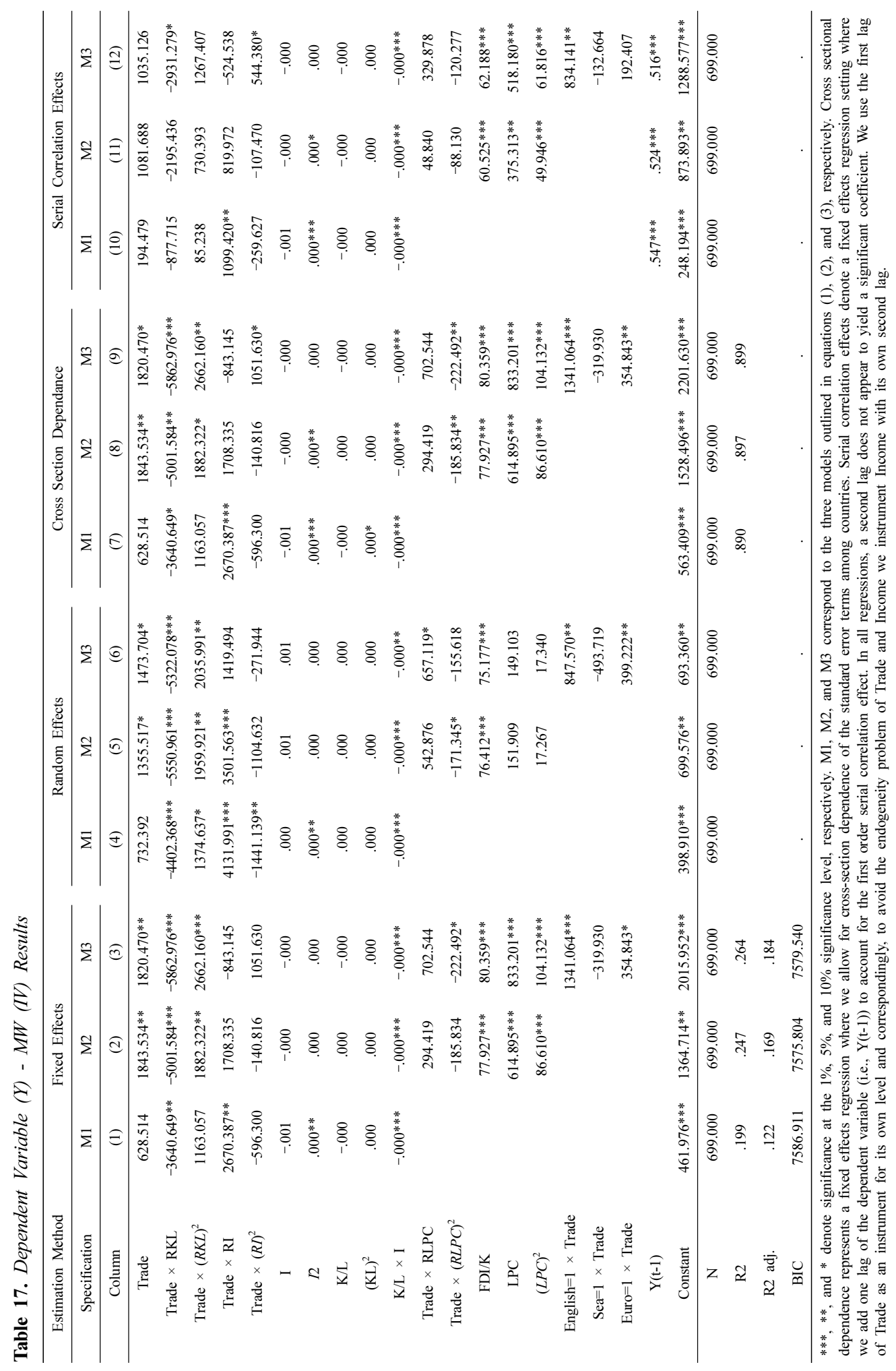


594 Journal of Economic Integration Vol. 36, No. 4

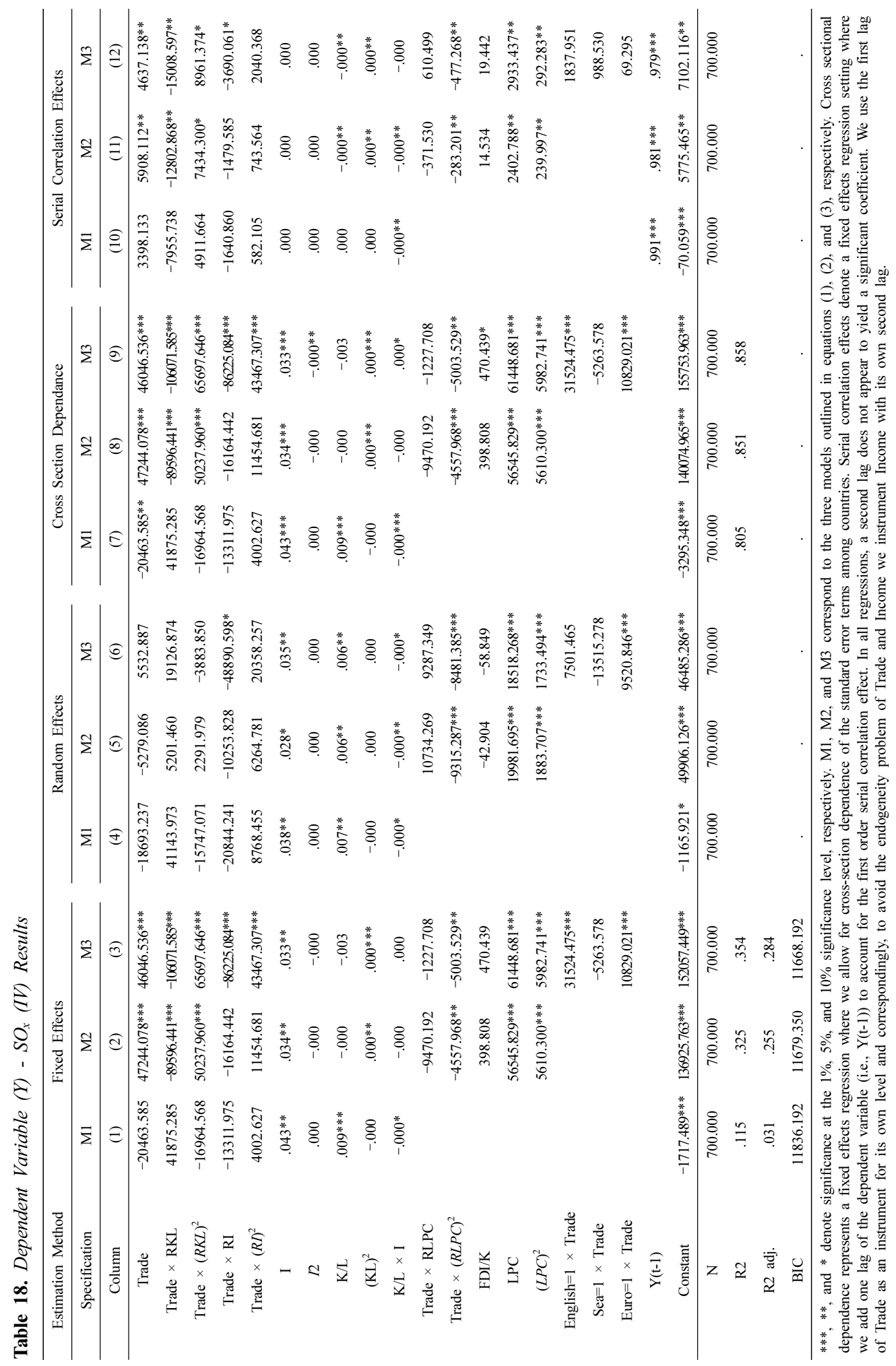




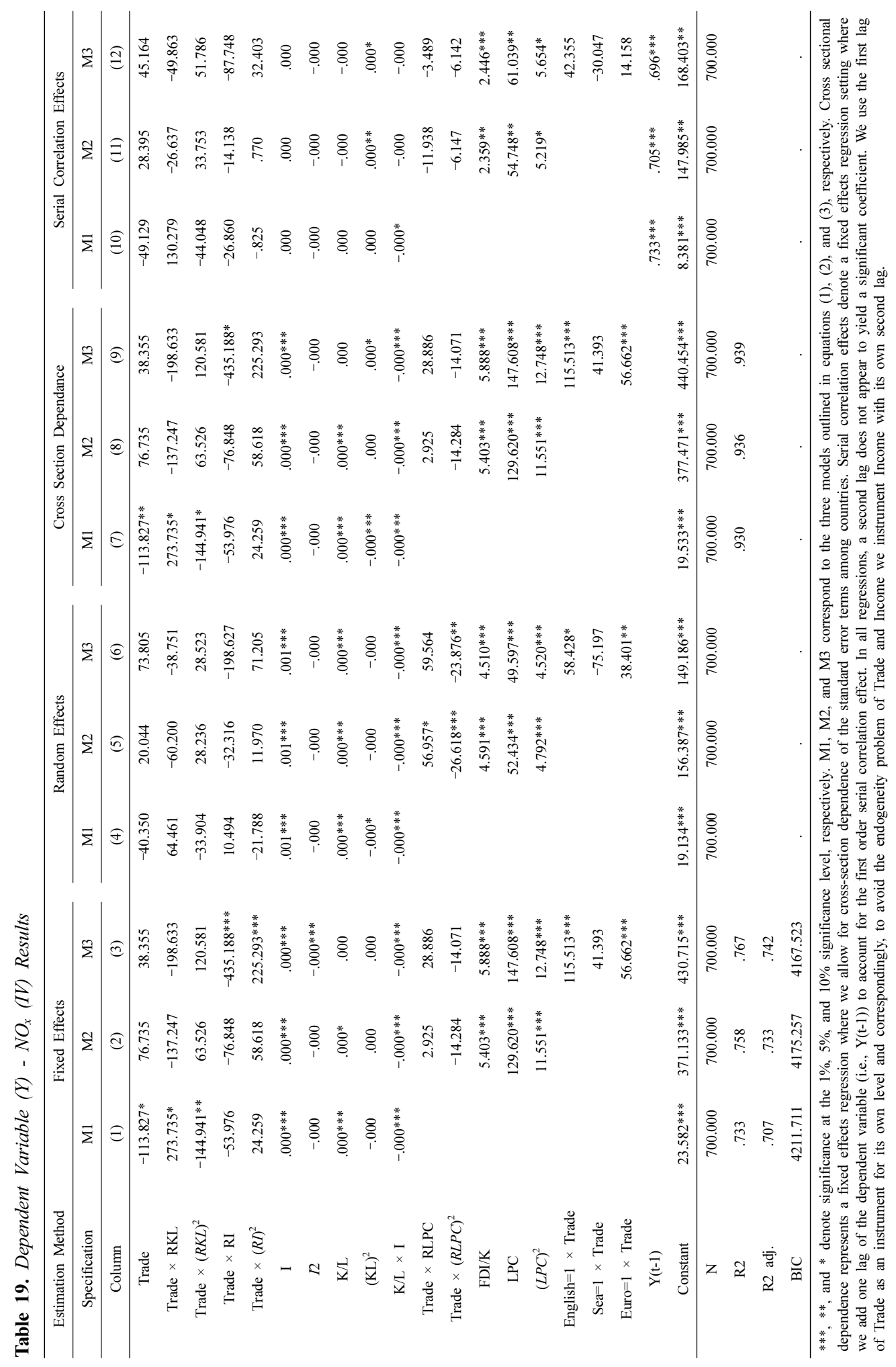




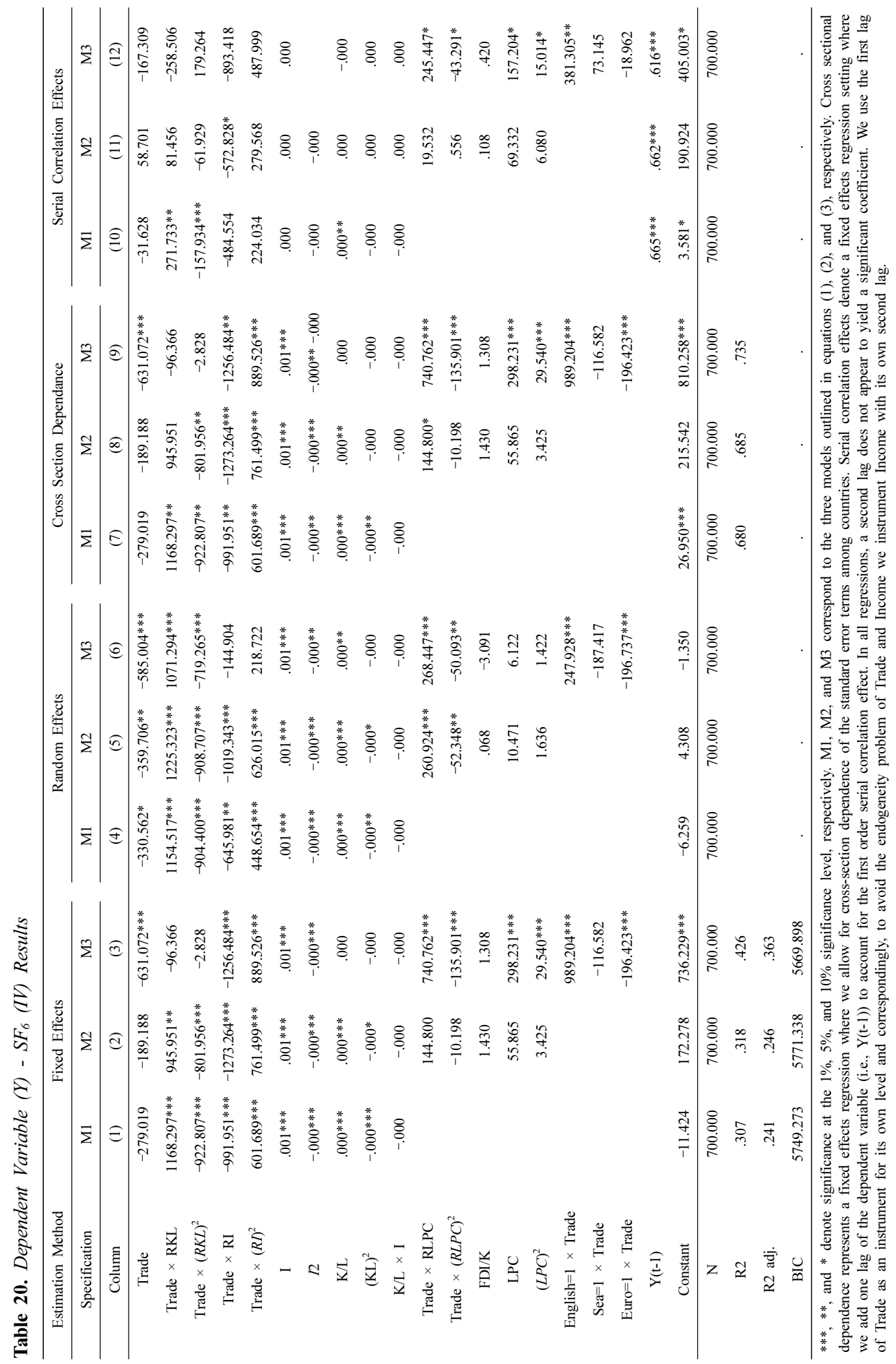




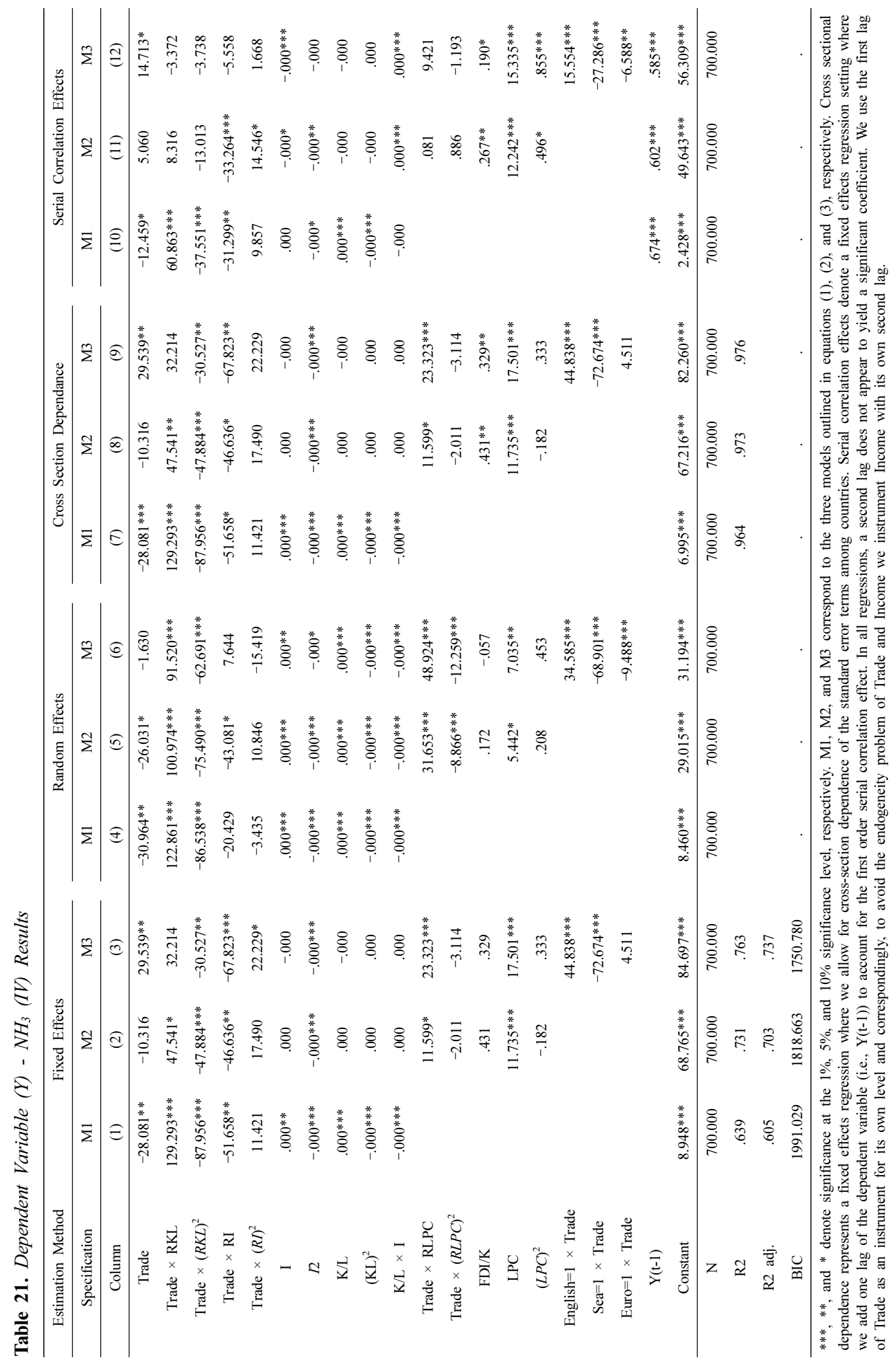




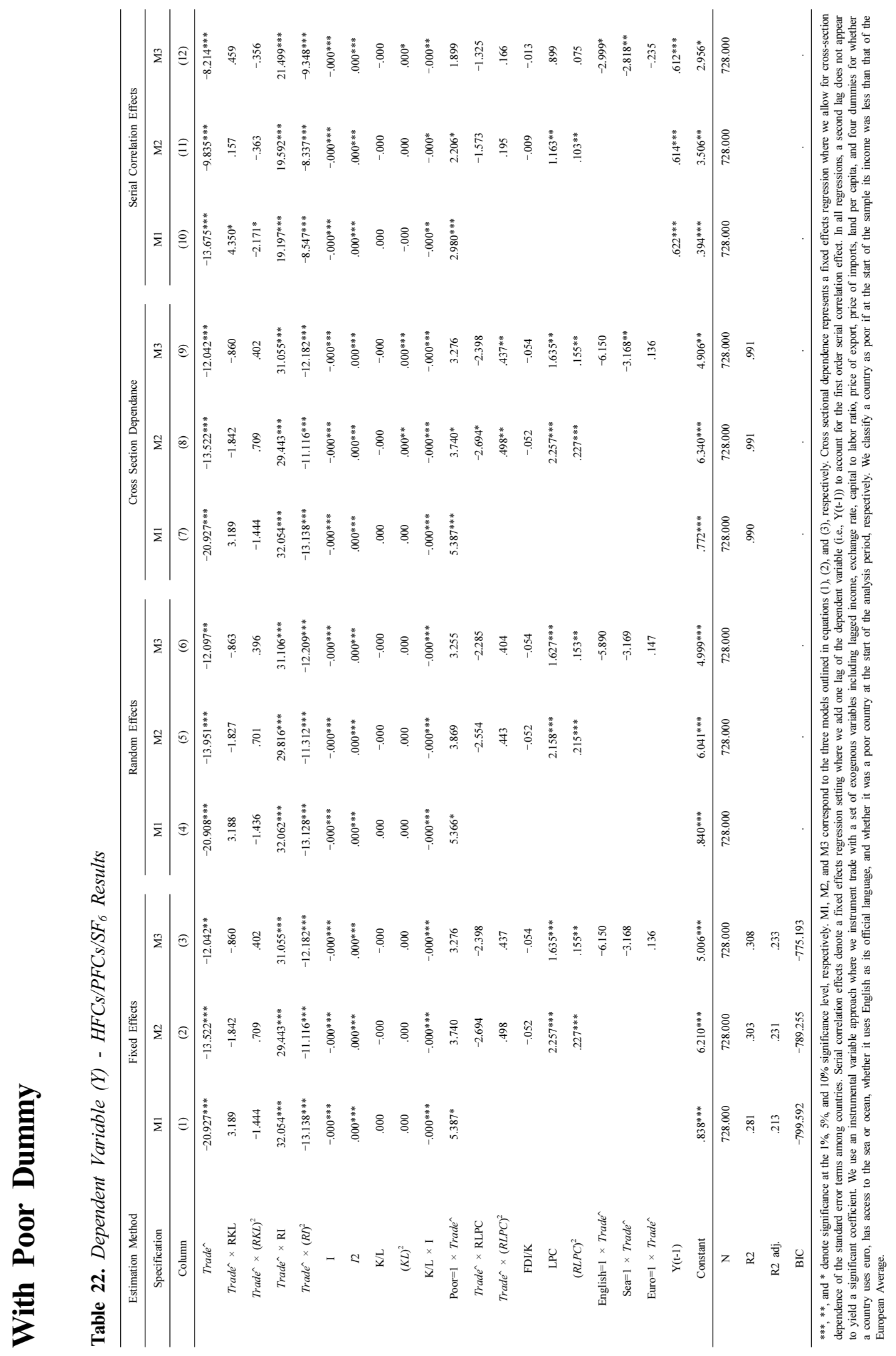




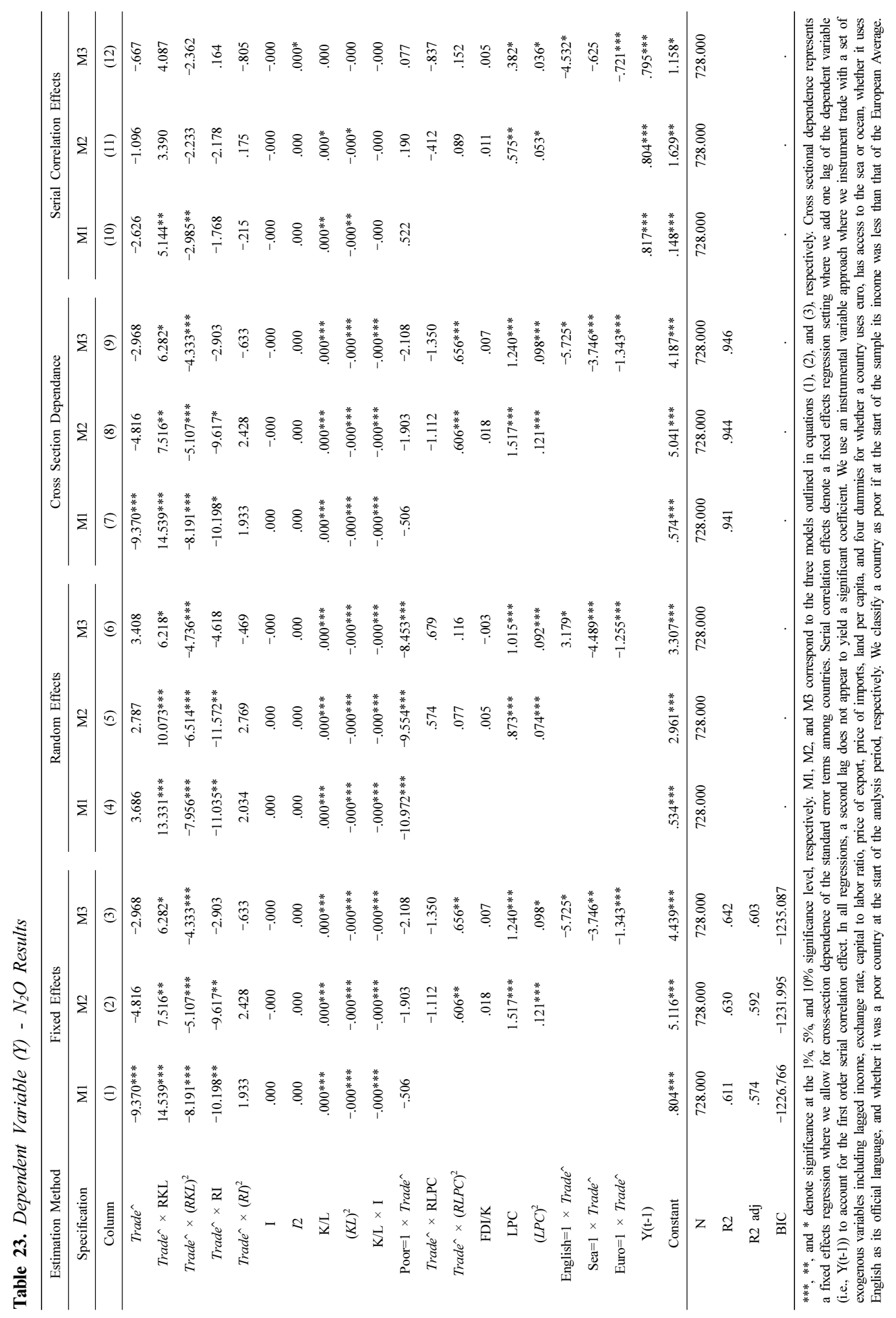




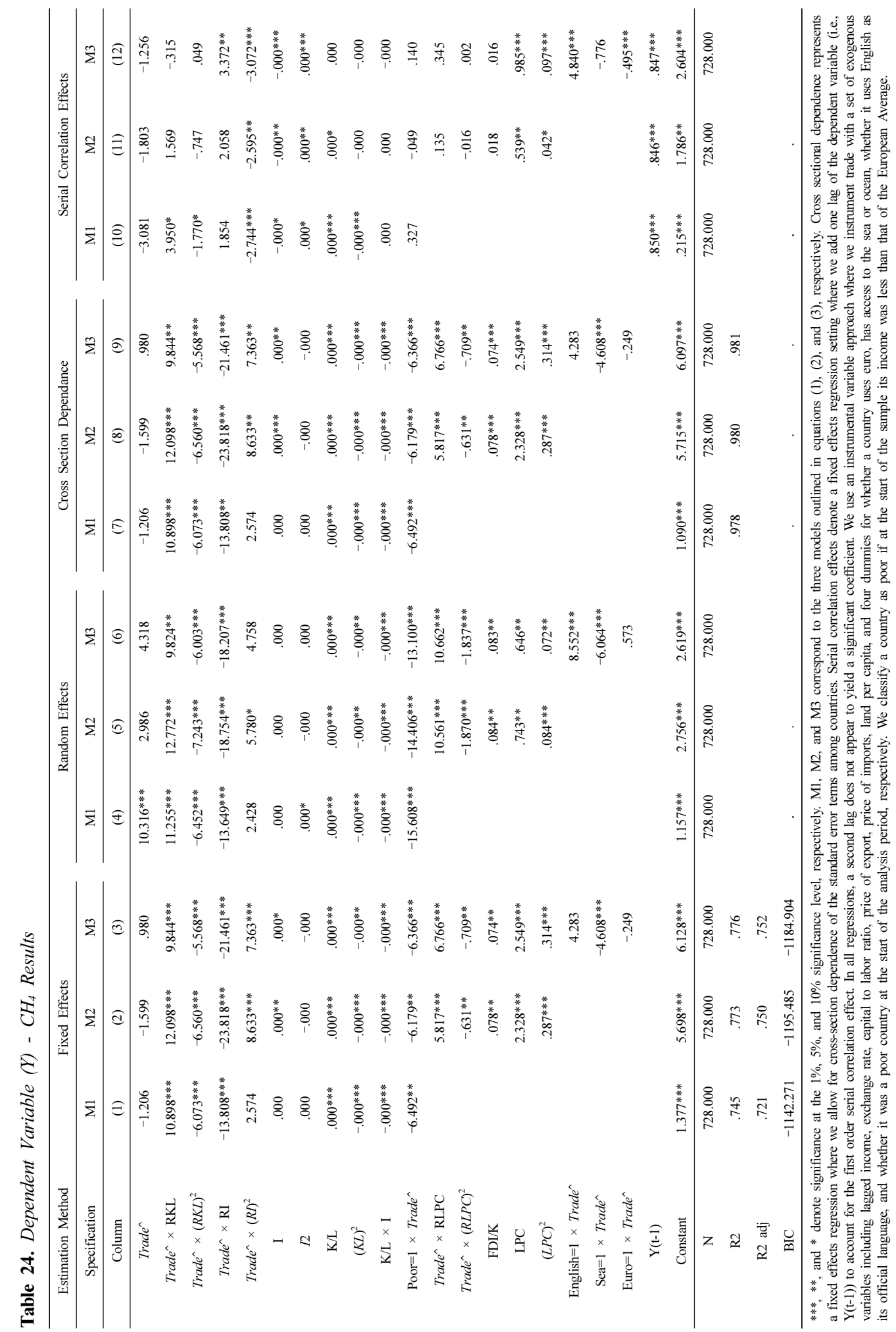




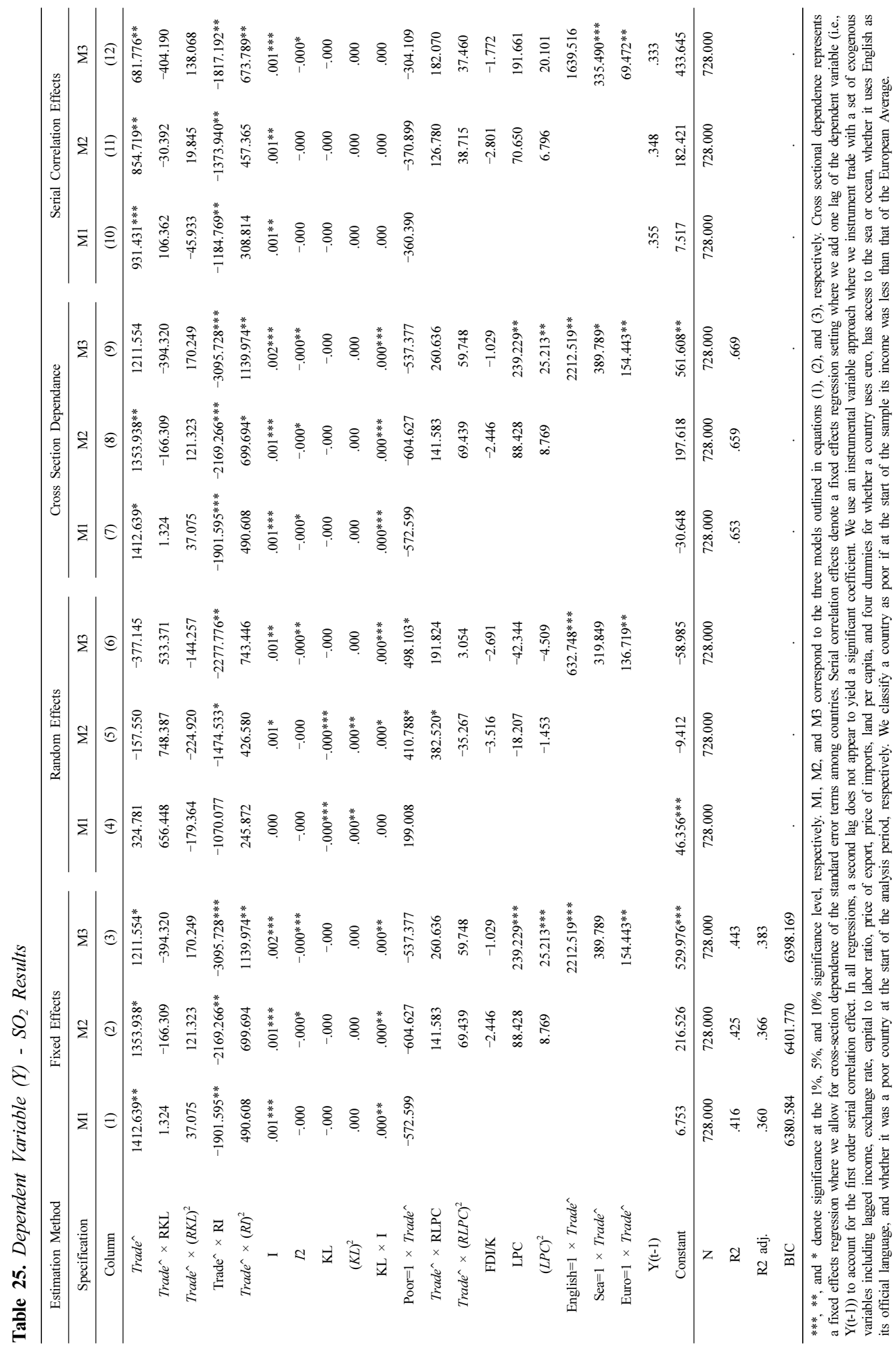




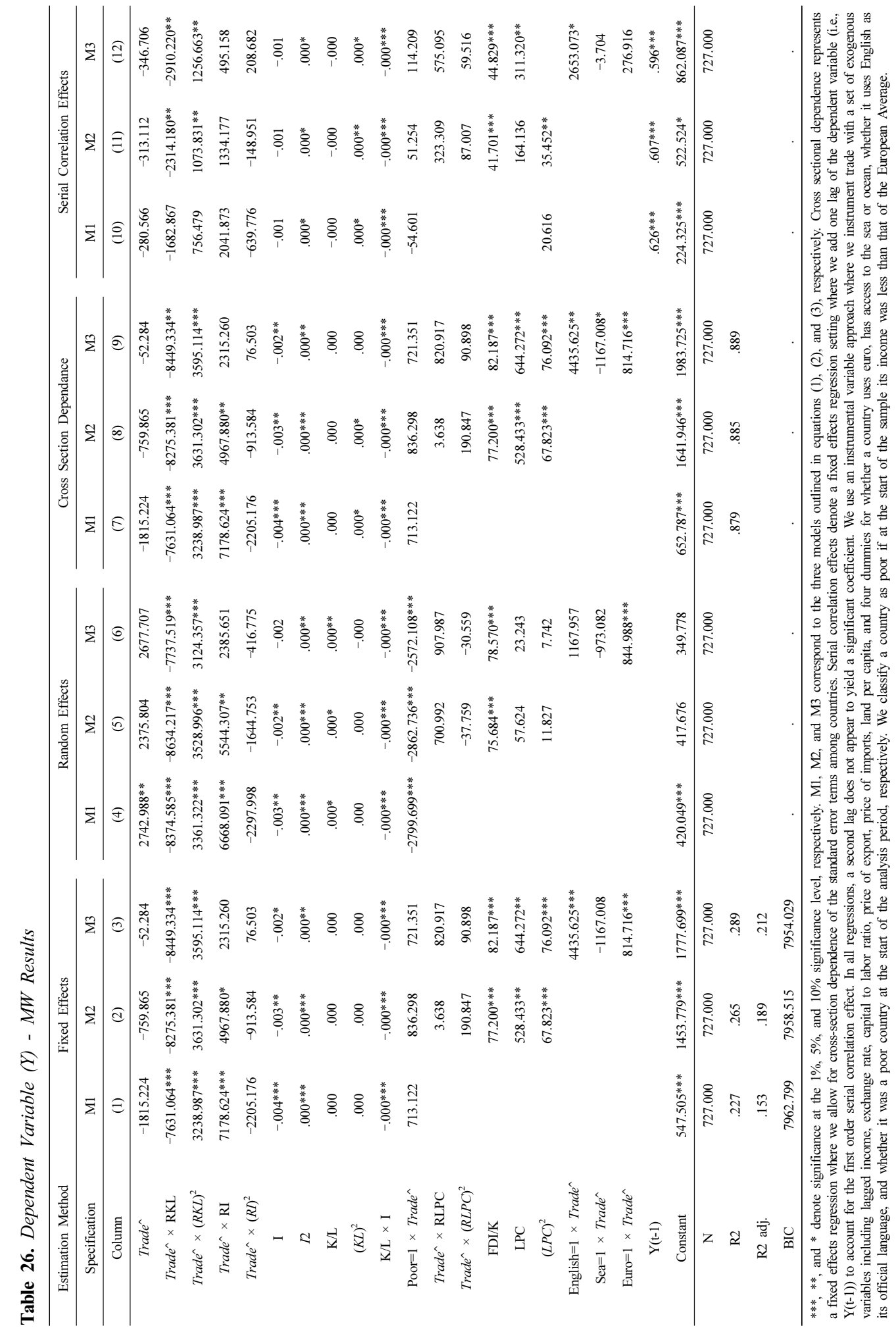




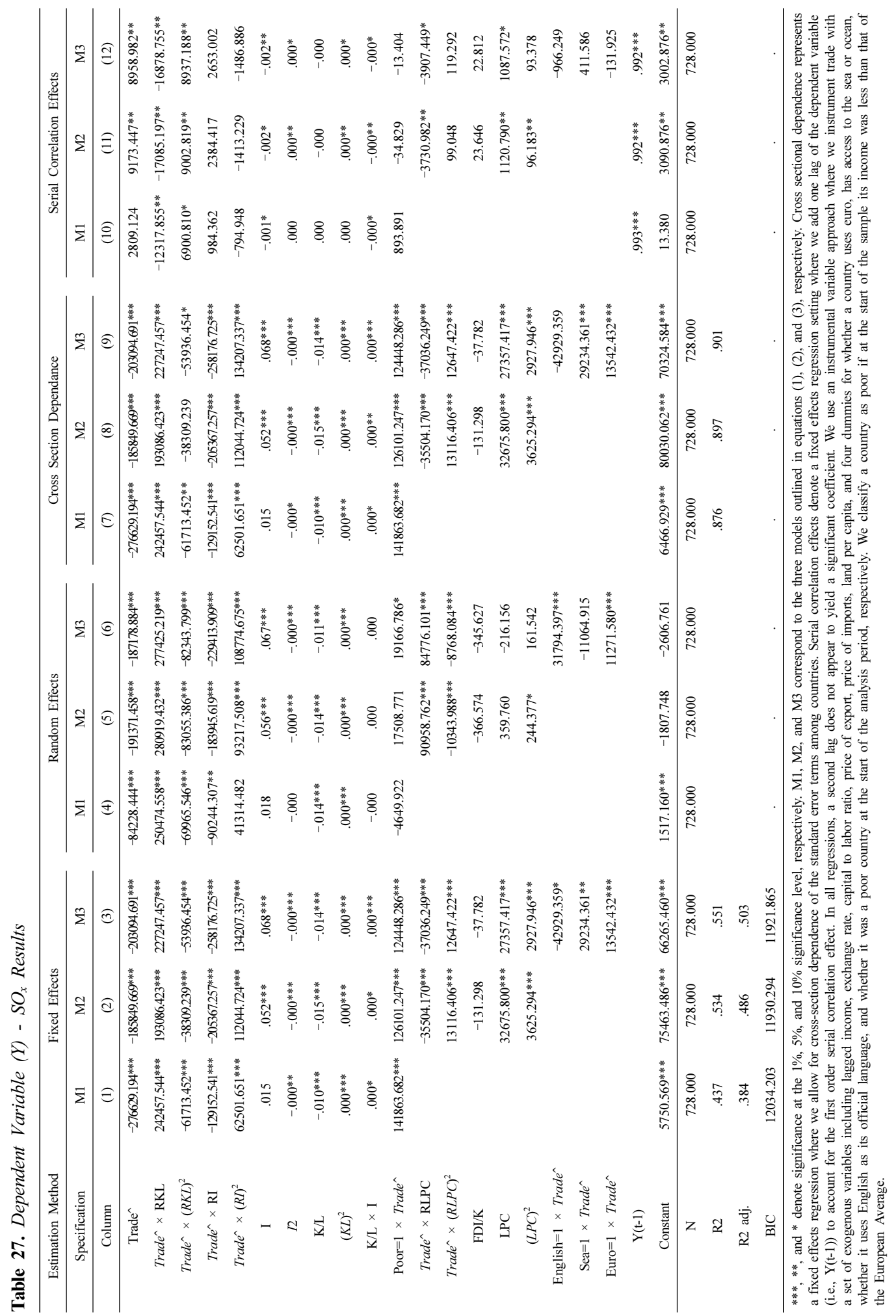


604 Journal of Economic Integration Vol. 36, No. 4

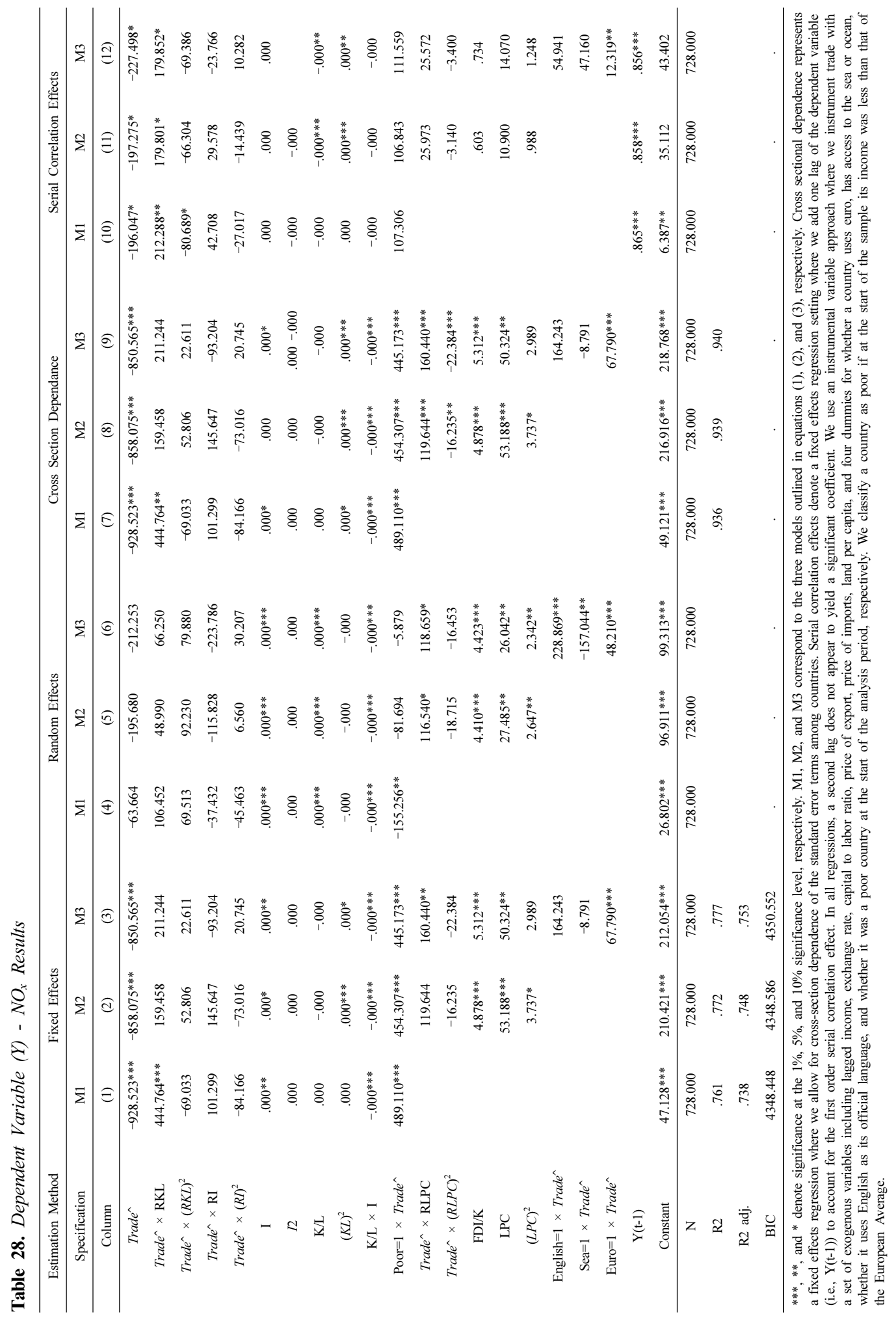




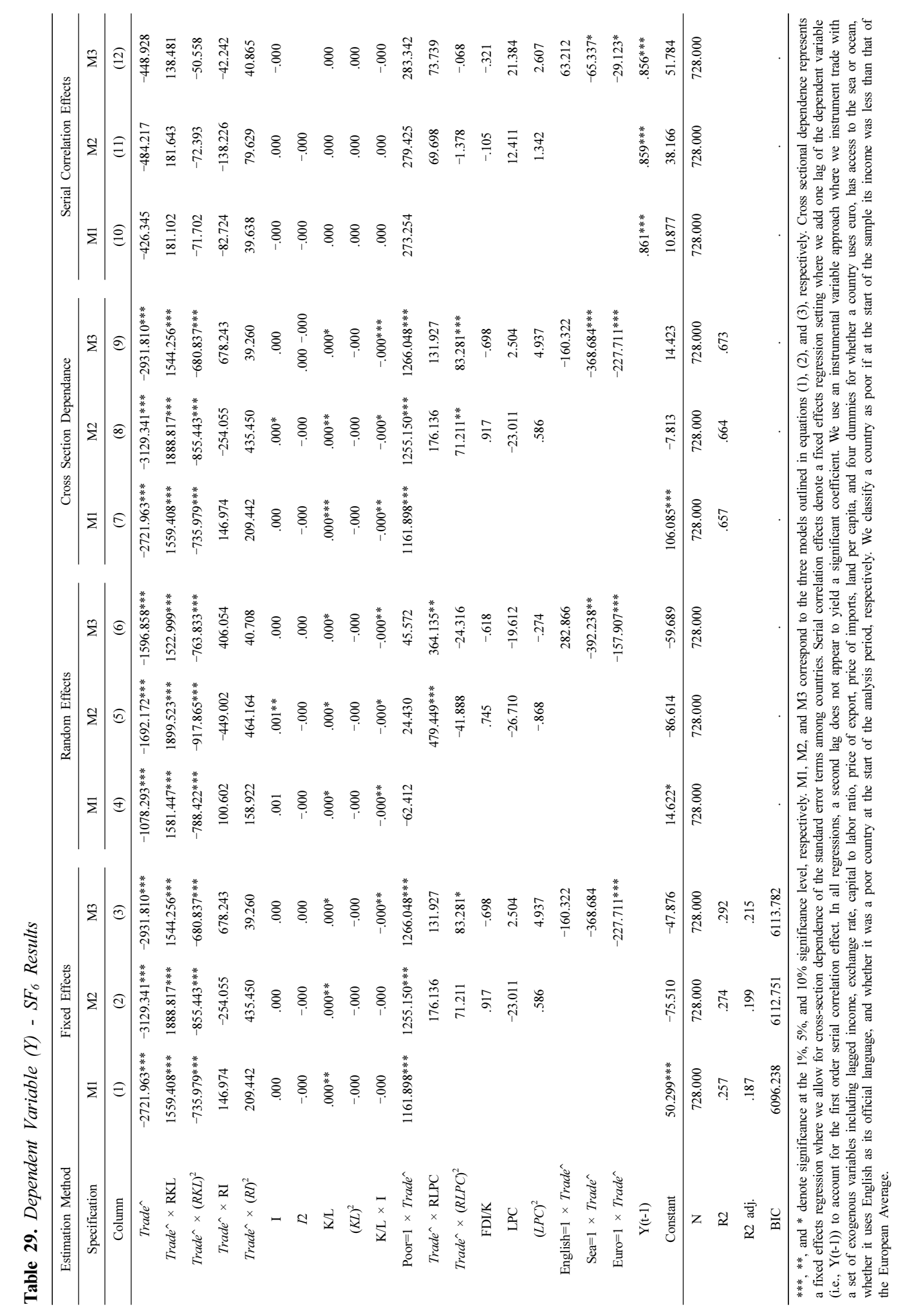




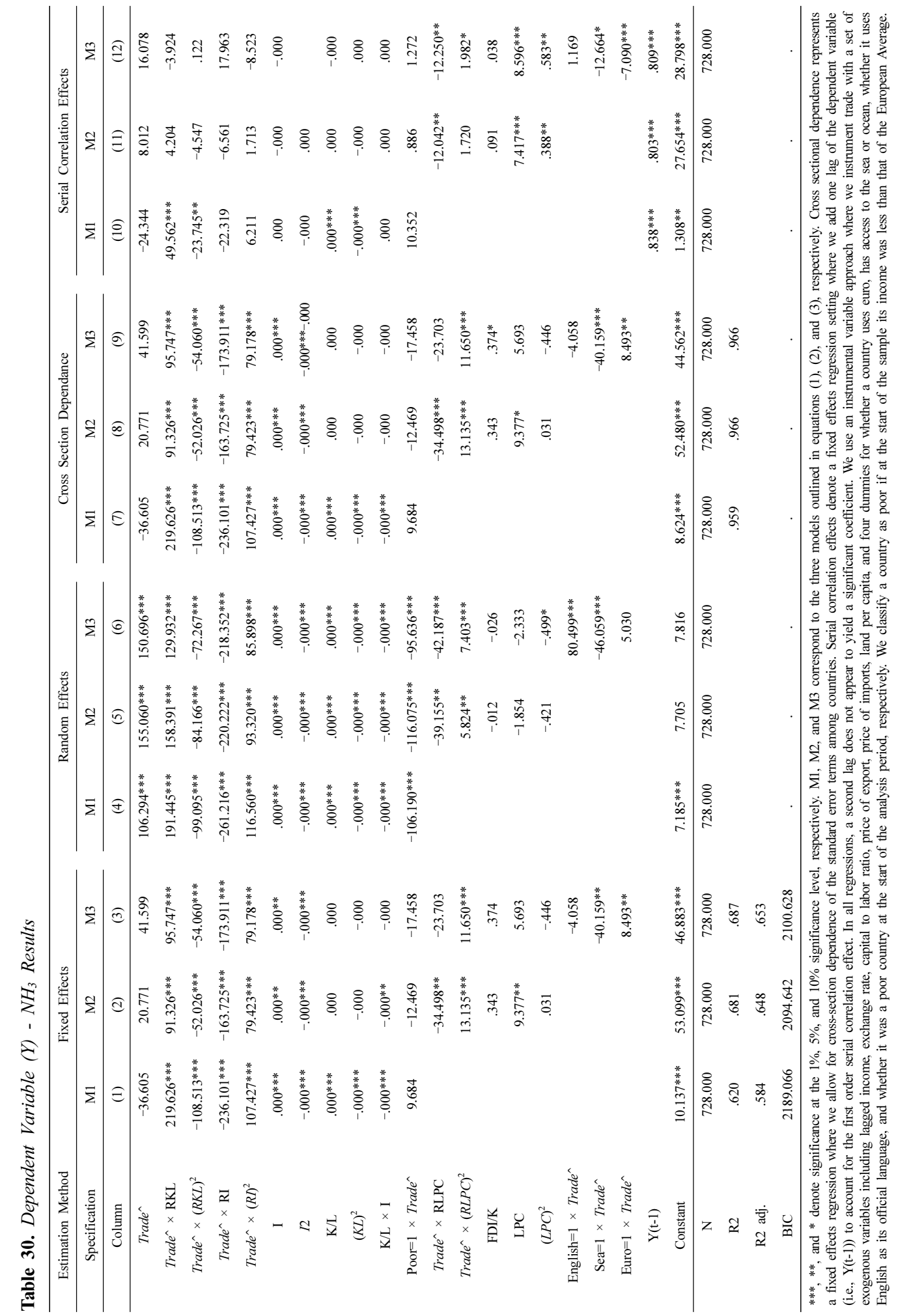

